was prepared as an account of work sponsored by an agency of the Unired States Government. Neither the United States Government nor any agency thereof, nor any of their employees, makes any warranty, express or implied, or assumes any legal liability or responsibility for che accuracy, completeness, or usefulness of any information, apparatus, product, or prosess disclosed, or represents that its use would not infringe privately owned rights. Refer-

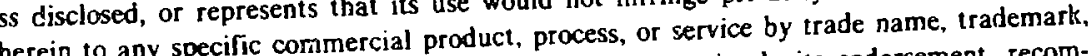
ence herein to any specific com not necessarily constitute or imply its endorsement, recommanufacturer, or otherwise does not States Government or any agency thereof. The views mendation, or favoring by the United herein do not necessarily state or reflect those of the and opinions of authors expressed herein do
Distribution Category:

High-Level Radioactive Waste

Management (UC-810)

\author{
ARGONNE NATIONAL LABORATORY \\ 9700 South Cass Avenue \\ Argonne, Illinois 60439
}

ANL $--90 / 21$

ANL-90/21

DE90 015839

\title{
STRATEGY FOR EXPERIMENTAL VALIDATION OF WASTE PACKAGE PERFORMANCE ASSESSMENT
}

\author{
by
}

J. K. Bates, T. A. Abrajano, Jr., D. J. Wronkiewicz

T. J. Gerding, and C. A. Seils

Chemical Technology Division

July 1990

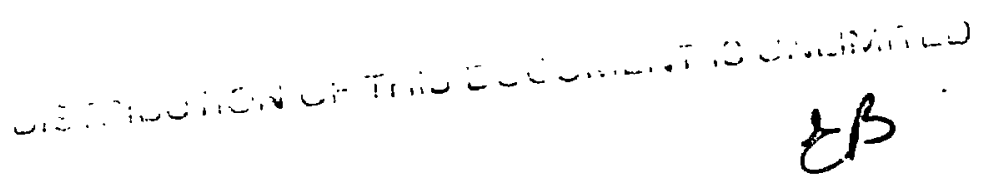




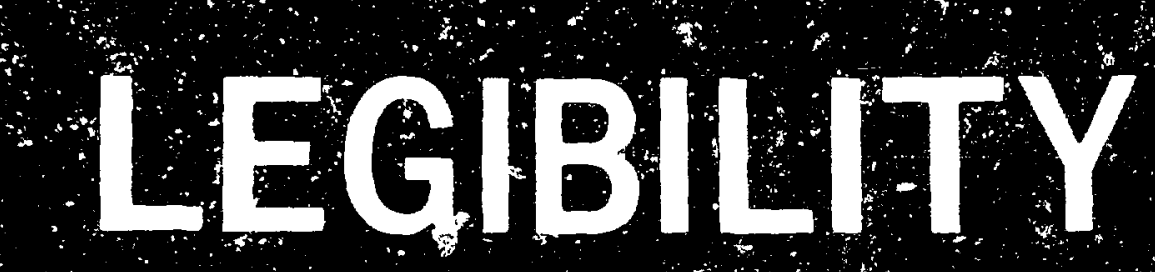

A major purpose of the Technical Information Center is to provide the broadest dissemination possible of information contained in DOE's Research and Development Reports to business, industry, the academic community, and federal, state and local governments.

Aithough a small portion of this report is not reproducible, it is being made available to expedite the availability of information on the research discussed herein. 


\section{IABRT OF CONTENTS}

Page

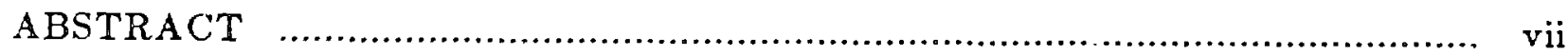

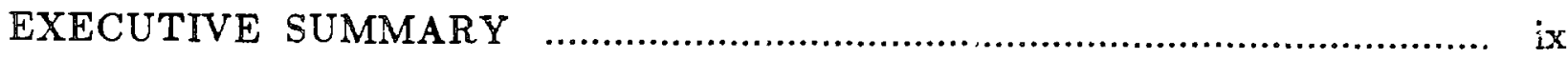

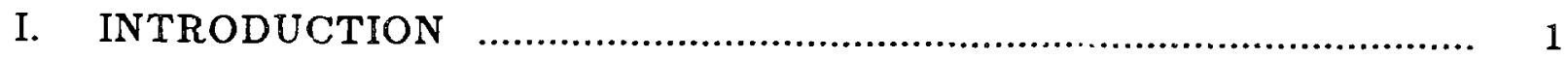

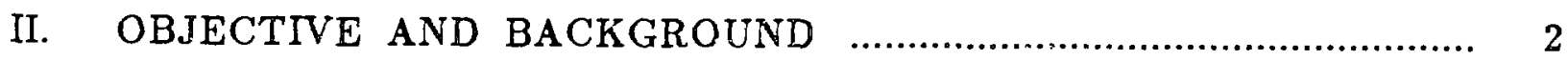

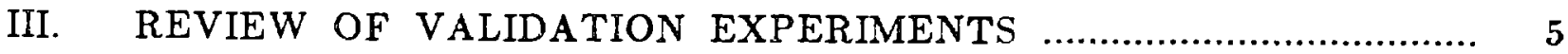

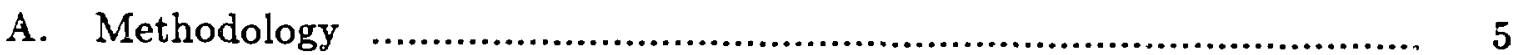

B. Review of Laboratory Analog Experiments ................................ 7

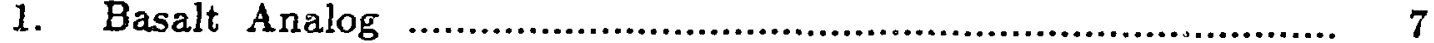

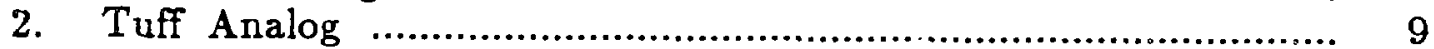

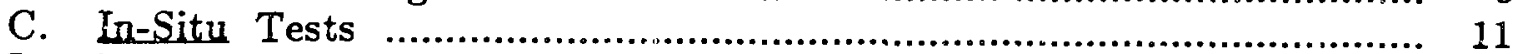

D. Repository Systems Simulation Tests in Granite .......................... 12

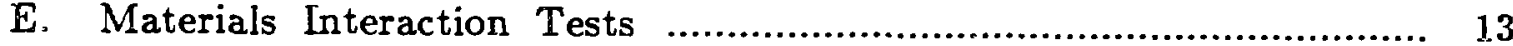

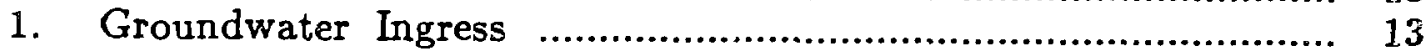

2. Waste Package Interactions ............................................. 15

3. Radionucliaje Migzation ............................................... 19

IV. SUMMARY OF IMPORTANT EXPERIMENTAL FACTORS .......... 24

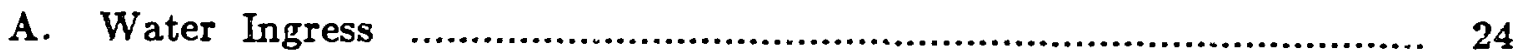

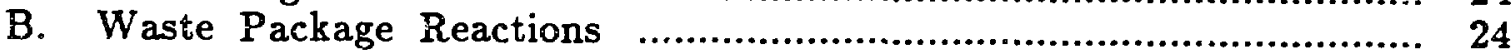

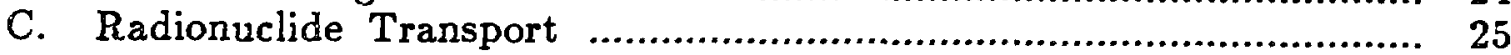

V. STR.ATEGY FOR EXPERIMENTAL VALIDATION OF

NEAR-FIELD PERFORMANCE ASSESSMENT …......................... 26

VI. METHODOLOGY DEVELOPMENT FOR LABORATORY

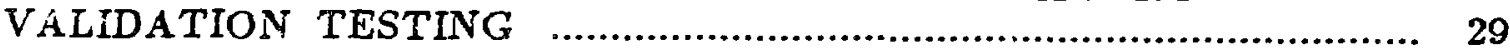

A. Testing Methodology, Objective and Background ....................... 29

B. Experimental Approach ......................................................... 29

1. Degree of Cavity Saturation ............................................ 31

2. Modificutions of Apparatus to Allow for

Data Measurement ............................................................. $\quad 36$

3. Use of Modified Unsaturated Test Apparatus
for Coupled System Validation ...................................... 39

VII. SUMMARY AND CONCLUSIONS ........................................... 41

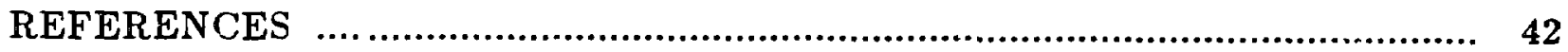




\section{IUIST OF TCABLES}

No.

Title

Page

1. Materials Interactions and Associated Yariables That Determine Waste Package Performance

2. Analog Experiments Conducted in the Program 


\section{UIST OTF EIGURES}

No.

Title

1. Outline of Proposed Standard Practice for Development and Validation of Waste Package Materials Performance Models

2. Diagra.n of Analog Test Apparatus and Kock Core ............................ 10

3. Representation of the Validation Test Apparatus with Glass as the Waste Form; Schematic Drawing of the Validation Test Apparatus without the Waste Form

4. Schematic Drawing of the Apparatus used to Measure whe Water Volume Collected in the Tuff Cavity

5. Measurement of Volume Level in the Tuff Cavity Using Selected Solutions and Temperatures

6. Measurement of the Conductance of the Water Collected in the Assembled Test Apparatus

7. Alternative Configurations of the Experimental

Validation Apparatus to Allow for Solution. Sampling and Controlled Water Input

8. Possible Alterations that Could be Made to the Apparatus to Simplify the Measurement of Radionuclide Transport

9. Drawing of the Apparatus Used in the Unsaturated Test Method 


\title{
STRATEGY FOR EXPERMMENTAL VALIDATION OF WASTE PACKAGE PERTORNANCE ASSESSMENT
}

by

J. K. Bates, T. A. Abrajano, Jr., D. J. Wronkiewicz

T. J. Gerding, and C. A. Seils

\begin{abstract}
A strategy for the experimental validation of waste package performance assessinent has been developed as part of a program supported by the Repository Technology Program. The strategy was developed by reviewing the resuits of laboratory analog experiments, in-situ tests, repository simulation tests, and material interaction tests. As a result of the review, a listing of dependent and independent variables that influence (1) the ingress of water into the near-field environment, (2) the reaction between water and the waste form, and (3) the transport of radionuclides from the near-field environment was developed. The variables necessary to incorporate into an experimental validation strategy were chosen by identifying those which had the greatest effect of each of the three major events, i.e., groundwater ingress, waste package reactions, and radionuclide transport. The methodology to perform validation experiments was examined by utilizing an existing laboratory analog approach developed for unsaturated testing of glass waste forms.
\end{abstract}




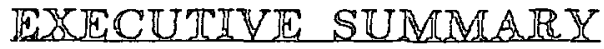

Waste package performance assessment models will be utilized in assessing the long-term containment performance of the waste packages, the long-term radionuclide release performance of the engineered barrier system (EBS), and the source term for the total repository system performance assessments. This report describes the results of an initial study of strategies that might be implemented for validating waste package performance assessment models. Although the work described herein predared the publication of the validation methodology that vas developed by the Office of Civilian Radioactive Waste Management (OCRWM) Validation Oversight Group (VOG), it is generally consistent with the VOG methodology.

This report reviews laboratory methodologies that can be used to critically test performance assessment models and their premises, and addresses the questions:

1. Are all of the important phenomena that influence the radionuclide release performance of a breached waste package considered in the modeling?

2. Are the models adequate to describe the observed performance of the system when the combined effects that may be important in the real system are introduced?

To evaluate experimental strategies, it is essential to have the best possible description of the materials and the environment because this information establishes the manner by which the materials react, and forms the basis for the development of submodels that feed into an overall PA model. For the YMP site there are still open questions regarding materials and the environment. Additionally, many independent variables that affect reaction processes vary with time such that a range of conditions exist. We address uncertainties in independent variables by suggesting that bounding values of the parameters be used to conduct model development and testing. Bounding conditions are those values for parameters that result in the most rapid degradation of the material. Care must be taken in choosing a bounding value for a parameter so that no synergisms occur with other parameters that would result in an overall slowing of the degradation rate.

Once the materials, environment, and bounding conditions have been established, alteration modes are identified and dependent variables are established by which to measure the extent of degradation or reaction. These dependent variables provide the information necessary to perform modeling (both development and validation) and must be measured throughout the testing program.

As a basis for identifying the alteration modes, materials interactions, and dependent variables that are desmed important to the projection of repository performance, and to determir.e the type of data that can be generated from laboratory experiments, a thorough review was conducted of previously performed laboratory analog tests, tests involving materials interactions, and planned tests to study integrated effects. 
Three major events were identified as being crucial for the evaluation of repository pe-formance. The events are (1) groundwater ingress, (2) waste package reaction, and (3) radionuclide transport. For each event, independent and dependent variables were identified. The number of variables that significantly influence the output from each event were reduced by review of each process. In summary, the key parameters for each event are:

(1) Water Ingress - The dependent variable that results from groundwater ingress is the composition of the solution when it contacts the waste package. The chemistry of $J-13$ water seems relatively invariant as a function of physical parameters that may affect the rock during the isolation and containment periods. As a function of temperature, it takes considerable time to equilibrate the water with the rock, but no dramatic changes in the composition of the water reaching the borehole boundary are anticipated.

To provide input to the waste package reaction event, a description of the solution must include the composition with respect to cations, anions, and radionuclides that may be present due to reaction with other waste packages; and the $\mathrm{pH}$ and Eh. A factor further complicating groundwater ingress is sorption of water vapor onto the waste form surface. While the composition of this water would reflect the waste form reaction process and not the water composition in the near field, the important factor is that the water is available to reac: with the waste and for transport of radionuclides.

(2) Waste Package Reacion - There are two key parameters that affect waste package reaction: (1) the amount of water present, and (2) the "aging" of the waste and container materials. Under saturated conditions, kinetic or nucleation effects appear to retard the attainment of true long-term steady-state reaction rates. This is especially true when the water/waste reaction is initiated in a large volume of water as opposed to attaining saturation through a gradual buildup of water. The effects of potential interactions, e.g., radiation, metal corrosion, etc., are, to an extent, mitigated by the volume of water. Thus, with smaller volumes of water as are present under unsaturated conditions, interactions are accentuated. In addition, the chemical form in which material is reizased from the waste form and is thereby available for transport varies. In unsaturated conditions, because of wet/dry cycling, material can be released as solids as opposed to actually being dissolyed in solution.

The other key parameter, aging, varies with the waste form. Glass will react in humid air by what is essentially a hydration in-situ devitrification process. When liquid water contacts glass, there will likely have been considerable alteration that has occurred that will affect subsequent reaction. Spent fuel will oxidize, thereby becoming more reactive. The rate of oxidation decreases with temperature, but 
the length of time available for oxidation may offset the lower temperature resulting in fuel with a mixed degree of oxiciation.

As with groundwater ingress, the dependent variable that is generated during waste package reaction is the description of the solution as it leaves the waste package. The description of the solution must include the composition with respect to cations, anions, and radionuclides.

The form of the radionuclides must also be identified with respect to speciation and whether the radionuclide is truly in solution or is associated with colloidal material.

(3) Radionuclide Transport - In summary, experimental validation of radionuclide transport models in tuff can be accomplished in saturated systems if the following parameters (independent variables) can be specified: (1) solution composition (colloidal fraction), (2) radionuclide speciation, (3) $\mathrm{K}_{\mathrm{d}}$, (4) $\mathrm{D}_{\mathrm{app}}$, (5) $\rho_{\mathrm{r}}$, (6) $\lambda$, (7) $\mathrm{b}$, (8) $\mathrm{v}_{\mathrm{x}}$, and (9) hydrodynamic dispersion coefficients. The latter parameters, although not discussed at length in this report, may or may not be critical depending on the experimental design. $D_{\text {app }}$ is a derived parameter that could be either experimentally measured or estimated from more fundamental parameters $\left(\mathrm{D}, \epsilon_{\mathrm{p}}, \alpha, \tau, \mathrm{K}_{\mathrm{d}}, \rho_{\mathrm{r}}\right)$; the same can be said for $K_{d}$ and $v_{x}$. In unsaturated systems, an added consideration is the degree of pore or fracture saturation in the tuff. The dependent variable that results from radionuclide transport is the distribution of radionuclides between the solution and the tuff. This can be measured by analysis of both the solution and the tuff.

An experimental methodology used to validate performance models must then account for and measure the important dependent and independent variables noted for each event. A review of existing methodologies indicates that the experimental approaches now exist and are being used to evaluate glass reaction in an unsaturated environment that could be adapted for validation of PA codes. Initial validation attempts would necessitate simplifications by both the PA codes and the experimental approach. More sophisticated validation studies would be developed as the description of the Yucca Mountain site and the repository horizon and waste package design matures. 


\section{STRATEGY FOR EXPERIMENTAL VALIDATION OF WASTE PACKAGE PERFORMANCE ASSESSMENT}

\section{INTRODUCTION}

Waste package performance assessment models will be utilized in assessing the long-term containment performance of the waste packages, the long-term radionuclide release performance of the engineered barrier system (EBS), and the source term for the total repository system performance assessments. A four-step strategy has been identified for performing these assessments [1]. The third step in this strategy is to "predict the rate of radionuclide release from a breached container" associated with an individual waste package. Models have been developed and are already being utilized for predicting such release [2-5]. Because the results obtained are being utilized to support near-term decisions concerning the acceptability of the Defense Waste Processing Facility (DWPF) glass waste form and also for guiding programmatic decisions concerning prioritization of information needs, it is important to begin to validate these models.

This report describes the results of an initial study of strategies that might be implemented for validating waste package performance assessment modols. Although the work described herein predated the publication of the validation methodology that was developed by the Office of Civilian Radioactive Waste Management (OCRWM) Validation Oversight Group (VOG) [6], it is generally consistent with the VOG methodology.

The overall metholology developed by the VOG contains the following general steps:

1. Maintain a record of model development.

2. Assess laboratory and field investigations to critically test the model and its premises.

3. Technical reviews.

The work described in this report addresses the second of these three steps by focusing on the design of laboratory analog experiments that can be utilized for waste package model validation. The experimental results can be utilized to address the following questions:

1. Are all of the important phenomeria that influence the radionuclide release performance of a breached waste package considered in the modeling?

2. Are the models adequate to describe the observed performance of the system when the combined effects that may be important in the real system are introduced?

The work described herein can, therefore, be considered as an initial effort in implementation of the VOG methodology. 
The development of a strategy for the experimental validation of performance assessment (PA) described in this report was supported by the Repository Technology Program. Strategy development will be done by performing (1) an evaluation of past testins approaches to identify the information that can be generated from experiments, and (2) a review of input required by PA models or submodels that have been developed to project repository performance to long time frames. The strategy that evolves from both reviews will be a synthesis of information needs and data availability, combined with a discussion of simplifications that may be required in both areas to develop a workable validation strategy. Finally, an assessment of experimental methodology is made to describe potential approaches for implementing the validation strategy.

\section{OBJECTIVE AND BACKGROUND}

The objective of this Task is to develop a strategy for validating PA modeling codes for near-field waste package/groundwater interactions over a range of conditions applicable to the proposed Yucra Mountain repository site. One validation approach is to conduct experimentation based on a laboratory analog or integrated test methodology, followed by comparison of the experimental results with those predicted by modeling. Such an approach appears straightforward, but since experimentation is used for both model development and model validation, a clear distinction between the experiments must be maintained such that experimental results used for generating models are not the same results as those used for validating models. Thus, validation experiments become a subset of the encompassing strategy, which is the extrapolation of data to long-term periods.

The ASTM committee C.26-13 has been addressing the extrapolation of data and the generation and validation of models used to describe waste package materials performance. The emphasis of the ASTM standard is on materials performance, but the same thought process can be used in the validation of PA. While the repositury program has no mandate to follow the ASTM standard, if it becomes accepted, the committee membership includes representatives from the Nuclear Regulatory Commission and the Department of Energy, and the final result will be a consensus of both producer and user groups. A partial outline of the proposed standard is shown in Fig. 1 , and an explanation of the standard as applied to validation experiments is provided below.

Section I of the standard is problem definition. In this activity, the materials and waste package environment and alteration modes are identified. It is essential to have the best possible description of the materials and the environment because this information establishes the manner by which the materials react, and forms the basis for the development of submodels that feed into an overall PA model. For the YMP site there are still open questions regarding materials and the environment. 


\section{PROBLEM DEFINITION}

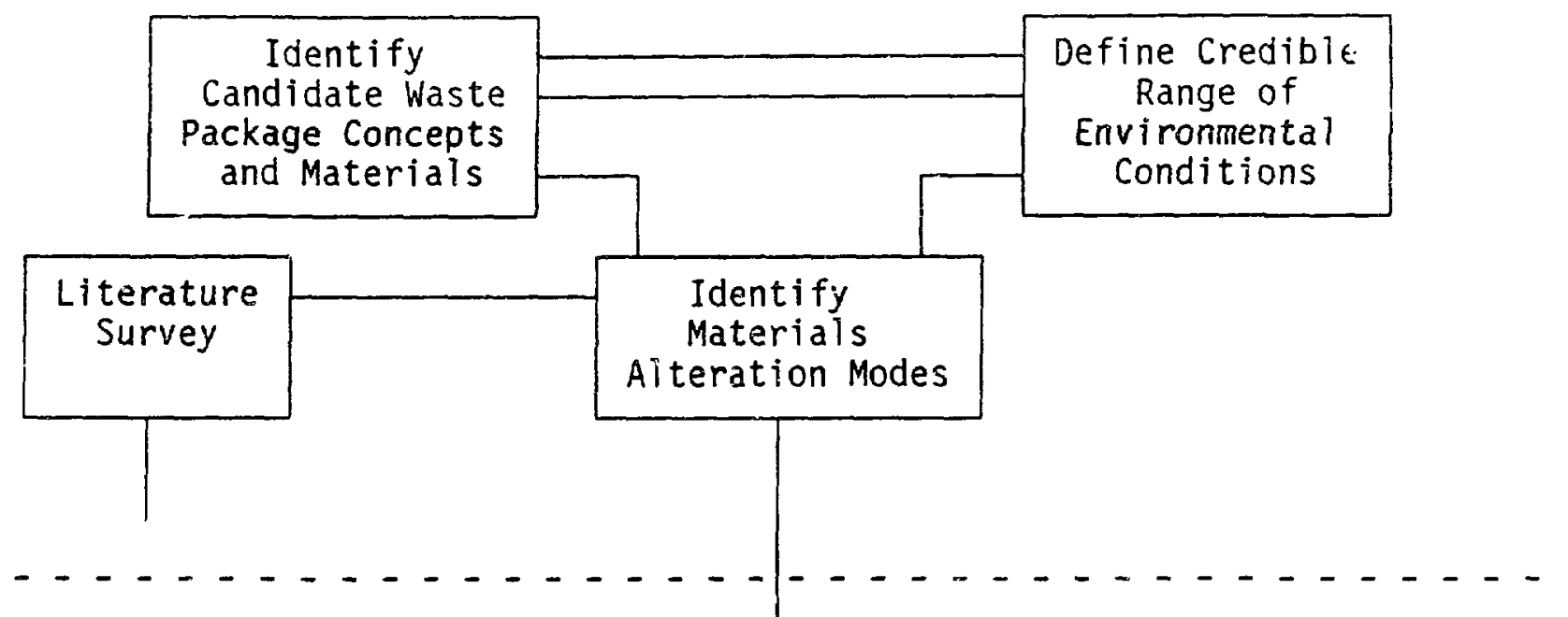

II. MODEL AND TEST DEVELOPMENT

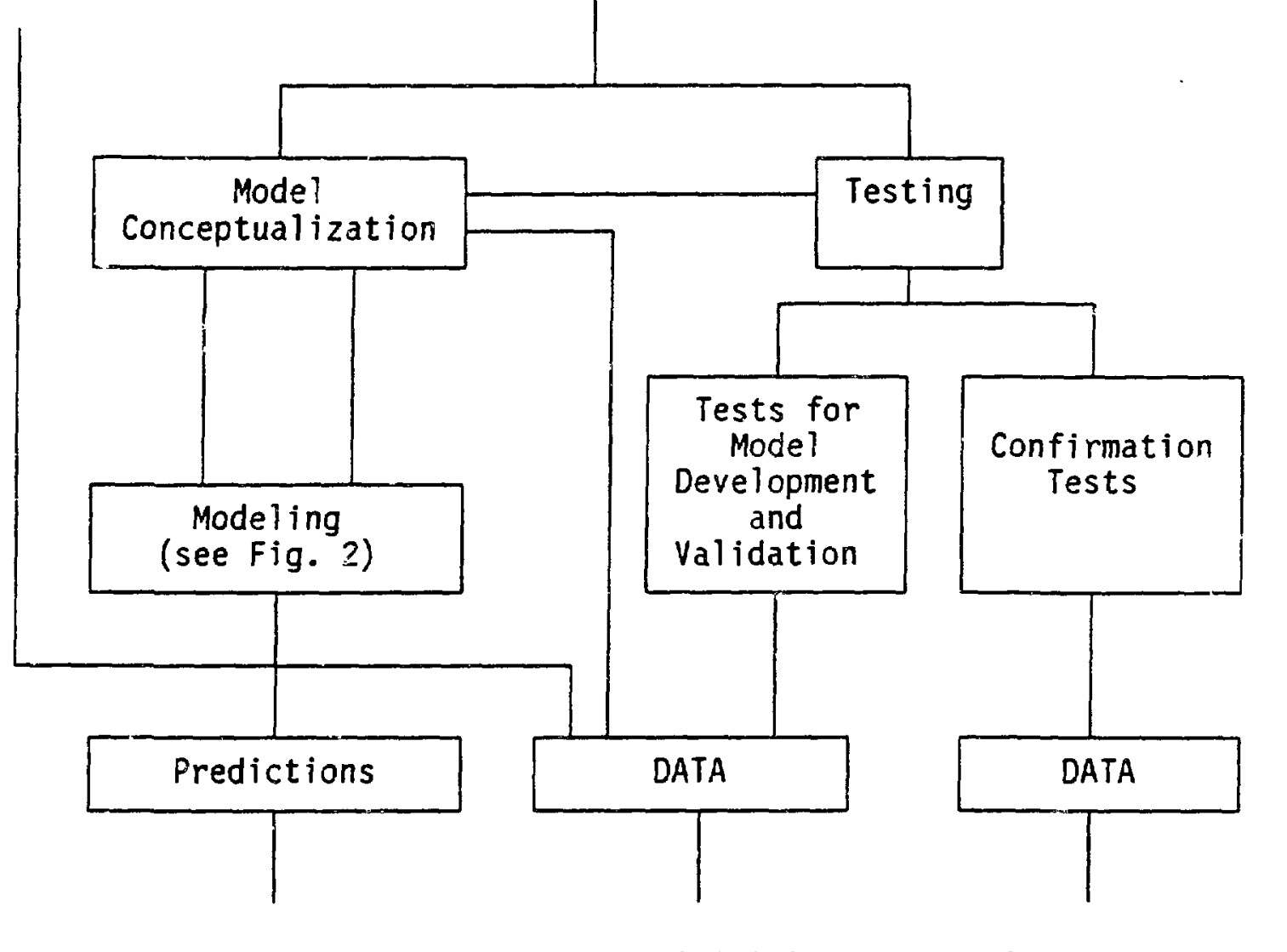

Fig. 1. Outline of Proposed Standard Practice for Development and Validation of Waste Package Materials Performance Models 
Additionally, many indeperdent variables that affect reaction processes vary with time such that a range of conditions exist. The standard addresses uncertainties in independent variables by sugresting that bounding values of the parameters be used to conduct model development and testing. Bounding conditions are those values for parameters that result in the most rapid degradation of the material. Care must be taken in choosing a bounding value for a parameter so that no synergisms occur with other parameters that woujd result in an overall slowing of the degradation rate.

Once the materials, environment, and bounding cr.ditions have been established, alteration modes are identified and dependent variables are estaklished by which to measure the extent of degradation or reaction. These dependent variables provide the information necessary to perform modeling (both development and validation) and must be measured throughout the testing program.

In Section II of the stardard, the relationship between modeling and testing is defined. Characterization or response tests measure the change in a dependent variable as a function of change in an independent variable. This type of information is used to develop submodels of materials performance. Accelerated or confirmation tests are tests performed independently of model development and are used to assess the ability of the model to predict events that are repository specific. If a match exists between the outcome predicted by the model and the data generated in long-term confirmation tests, model validity is indicated. To conduct confirmation tests, it is not necessary to have the submodels completely developed, but it is necessary to have identified the materials, the environment, and the dependent variables that measire the progress of an event.

To be successful in developing this type of confirmation test, a clear indication of required input fron PA modeling groups and an equally clear description of data that can be generated experimentally are required. In the following discussion; the basis for determining the required input for PA includes a focused review of the Yucca Mountain Site Characterization Plan and related PA documents. This review was to have formed the basis for direct discussions with the PA groups. These discussions would be used to establish a clear relationship between input required by $\mathrm{PA}$ and output that can be provided by testing. However, a workshop to discuss these ideas could not be scheduled. Thus, our evaluation of PA needs remains preliminary, and is based on the SCP review (Appendix I) and more importantly on on: i...derstanding of the submodels that combine to form an overall PA approach.

As a basis for identifying the alteration modes, materials interactions, and dependent variables that are deemed important to the projection of repository performance, and to determine the type of data that can be generated from laboratory experiments, a thorongh review was conducted of previously performed laboratory analog tests, tests involving materials interactions, and planned tests to study integrated effects. The identification of perceived PA needs, together with available experimental output, is discussed in the following section. The development of a validation strategy depends on how closely the two parts match, and what adjustments can be made by either modelers or experimentalists to simplify or bound the processes. 


\section{REVIEW OF VALTDATION EXPERIMENTS}

\section{A. Methodology}

The proposed repository site at Yucca Mountain, Nevada, is unique among proposed sites worldwide in that it is located in an unsaturated horizon. Thus, many factors that have been identified as important to the evaluation of saturated environments must be reevaluated as to their importance to performance of the Yucca Mountain site. However, three essential and sequential phenomena or events, generic to the evaluation of repository performance, can be used as a basis for evaluating past experimental approaches and for validating PA codes. These are:

(1) Groundwater Ingress - Groundwater comes is contact with the waste;

(2) Waste Package Reaction - The groundwater reacts with the waste and waste package components to degrade the waste and release radionuclides; and

(3) Radionuclide Transpcrt - Radionuclides are transported from the waste package into the near-field host rock environment. Eventually the radionuclides will be transported to the accessible environment; however, that part of the problem will not be addressed in this report.

Each of these three events or processes can be described by a submodel that when coupled together are key parts of the overall PA of ihe near field. To understand how each submodel is developed, it is necessary to identify the output of the submodel (dependent variables), and how the output is affected by changes to the input to the submodel (independent variables).

Table 1 provides a listing of materials interactions and physical parameters (independent variables) that can affect each of the three main events, and also identifies the key dependent variable that is generated for the event. It is important in developing an experimental strategy to recognize which parameters can influence the reaction process and to evaluate these parameters during experimentation. It is not necessary, however, to have a complete understanding of the effect of each parameter on the reaction progress before developing an experimental validation strategy and actually initiating experiments. In the following review, previously performed analog experiments will be examined and the effects of materials interactions as derived from simple experiments will be discussed. Dependent variables will be identified that can be monitored experimentally. Finally, a summary is given for each of the three events,

*In the context of this report, saturated is defined as the existence of a continuous direct water pathway between the waste and the near field, i.e., the borehole/container is filled with water. Unsaturated condition would be the lack of a continuous water pathway, i.e., humid air/dripping water. 
Table 1. Material Interactions and Associated Variables That Dotermine Waste Package Parformenco

\begin{tabular}{|c|c|c|c|c|}
\hline Events & Interections & $\begin{array}{l}\text { Physical Paramotors } \\
\text { (Indopendont Variables) }\end{array}$ & Processes" & $\begin{array}{l}\text { Dependont } \\
\text { Variable }\end{array}$ \\
\hline $\begin{array}{l}\text { Groundwater } \\
\text { Ingress }\end{array}$ & $\begin{array}{l}\text { Rock/Water/Air/ } \\
\text { Other Materials }\end{array}$ & $\begin{array}{l}\text { Tomperature, time, radiation, rock } \\
\text { composition, initial water composition, } \\
\text { dogree of eaturation, other matarials }\end{array}$ & $\begin{array}{l}\text { Dovitrification } \\
\text { hydration, } \\
\text { chamical reactica }\end{array}$ & $\begin{array}{l}\text { Solution } \\
\text { composition } \\
\text { contacting } \\
\text { wasto }\end{array}$ \\
\hline $\begin{array}{l}\text { Woste Package } \\
\text { Reactior }\end{array}$ & $\begin{array}{l}\text { Humid Air/Motal/ } \\
\text { Woste Form/Liquid Wotor/ } \\
\text { Other Materisls }\end{array}$ & $\begin{array}{l}\text { Solution corapositian in, temporature, time, } \\
\text { radiation, ralative humidity, motai } \\
\text { composition end trestment, weste form } \\
\text { composition, surface orea, volume of } \\
\text { water, localized redox environment, neture } \\
\text { of reactod leyers, gless devitriflication, } \\
\text { surface roughness, pH, gas composition } \\
\text { water flow, gless stross }\end{array}$ & $\begin{array}{l}\text { Motsl corrosion, } \\
\text { hydiation, } \\
\text { dissolutions } \\
\text { lon exchenge }\end{array}$ & $\begin{array}{l}\text { Solution } \\
\text { ecmposition } \\
\text { oftor } \\
\text { rosction } \\
\text { with yosto }\end{array}$ \\
\hline $\begin{array}{l}\text { Radionuelide } \\
\text { Transport }\end{array}$ & $\begin{array}{l}\text { Rock/Wator/Air/ } \\
\text { Radionuclides }\end{array}$ & $\begin{array}{l}\text { Solution composition in, Kd, Dapp: } \\
\text { Pr, } \lambda, b, v_{x} \text {, hydrouynamic dispereion } \\
\text { coefficionts, dogroo of saturation, } \\
\text { speciation of radionuclides }\end{array}$ & $\begin{array}{l}\text { Dissolution, } \\
\text { complexation, ion } \\
\text { axchenge, sorption. } \\
\text { procipitation }\end{array}$ & $\begin{array}{l}\text { Solution } \\
\text { composition } \\
\text { after noop- } \\
\text { pield }\end{array}$ \\
\hline
\end{tabular}

The processes listed are demonstrative and ney not be inclusive.

$y_{x}=$ uverago linear velocity of groundwater of low

$\mathrm{J}_{\text {app }}=$ diffusion coefficient for each radionuclido

$K_{d}=$ distribution coofficient for asch radionuclide

$\operatorname{Pr}=$ density of rock

b = Practure half width

$\boldsymbol{\gamma}=$ radionuclide decay conatant 
and parameters that appear to most greatly affect the outcome of the event are discussed. A validation strategy is then presented based on the ability to match the response of dependent variables that can be monitored experimentally with corresponding PA output.

\section{B. Raview of Laboratory Aralog Experiments}

A complete analog experiment is one in which all three events as indicated in Table 1 are incorporated into the experimental design. Experiments that have been deveioped fall into two categories: laboratory and in-situ tests. Laboratory experiments have been performed by Seitz $[7-26]$ as applied to a basalt environment and Bates $[27-5 \hat{j}]$ as applied to the Yucca Mountain tuff environment. There have been several in-situ experiments including tnose conducted at Stripa, Swedon [54-64]; the WIPP site [65-72]; Chalk River [73]; Mol, Belgium [74-76]; Ballidon, United Kingdom [77-78]; the Nevada Test Site

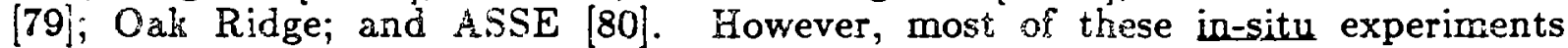
have focused mainly on the performance of the waste package, and thus provide only a partial assessment of repository performance.

1. Basalt Analog - The purpose of these experiments was to provide an understanding of interactions between reposit.ry components that may affect repository performance with respect to licensing iss ses. Specific issues addressed by the research are identified by [7] as:

(1) Do different metal alloys that are proposed for canisters of nuclear waste affect radioelement migration and, hence, potential repository performance?

(2) Does radiolysis of groundwater solutions affect radioelement migration and, hence, potential repository performance?

(3) Does alteration of repository components, such as is expected upon aging of a repository, defrade repository performance or does it improve repository periormance as commonly stated?

(4) What concepts and measurements (solubility products, leach rates, adsorption ratios, etc.) are sufficient to describe radioelement migration in systems with flowing groundwater?

(5) Are experimental programs that are undertaken to support repository development properly designed to address the subject of repository performance in the near and long terms?

General issues addressed in this work are:

(1) Do laboratory studies economically contribute to our general understanding of repository performance? 
(2) Cars we identify the interactions between repository components of most importance to repository performance under the conditions of the experiments? By corollary, can we demonstrate that some interactions are not important to issues of repository performance?

(3) Can we independently evaluate, using laboratory studies, commonly followed practices of repository design with regard io issues of repository performance?

(4) Cari we obtain sets of data on radioelement migration collected under accurately measured conditions of semperature, water flow, and water composition that could be used to test computer codes of radioelement migration?

To resolve these issues, a modular experimental approach was used in which in the first module groundwater was equilibrated with rock and backfill before contacting a glass waste form. The waste form was also included in the end of the first module. The groundwater was sampled before and after this module prior to passing into the second module which contained backfill. The water was sampled after flowing through the backfill and also through a fissure that had been introduced in a basalt core (third module). The modules were interconnected using candidate metals to be used in containment of the waste form. The purpose of the first nodule was to condition the groundwater using waste package components before contact with the waste form, combined with waste form reaction. The second module was to monitor the effectiveness of backfill in retarding radionuclide migration, and the third module was used to monitor radionuclide transport through a fracture in the host rock.

The experiments were run in six modes as listed in Table 2 adapted from [7]. The key effect that Seitz demonstrated in these experiments was the importance of "aging" the experimental components prior to reaction. Aging will occur in the waste package/near-field environment prior to containment breach, and thus the waste package and near-field components in a 1000-year-old repository will undoubtedly have different characteristics from those that were newly placed in the repository. Seitz found that aging had an effect on radionuclide release from the glass waste form and on radionuclide transport through the basalt fracture. Both the glass reaction and radionuclide transport were significantly increased using the aged components. The effects of metal and radiation were minor in comparison with aging.

Of course, the method used to age the experimental components is key in establishing a realistic experiment. Seitz used hydrothermal reaction to age both the glass and the rock. The justification for using this method was

\footnotetext{
Aging is defined as a combination of effects that alter the waste form properties prior to contact by liquid water. For glass, aging would consist of hydration by humid air, devitrification, and radiation damage. For spent fuel, aging would consist mainly of oxidation.
} 
Table 2. Aralog Experiments Conducted in the Program [8]

\begin{tabular}{|c|c|}
\hline $\begin{array}{l}\text { Analog } \\
\text { Experiment } \\
\text { Number }\end{array}$ & $\begin{array}{l}\text { Simulated Repository Conditions } \\
\text { and Experimental Varianles }\end{array}$ \\
\hline 1 & $\begin{array}{l}\text { Recently constructed repository using Hastelloy C-276 } \\
\text { alloy with as-manufactured waste glass, backfill, and } \\
\text { recently fissured basalt. }\end{array}$ \\
\hline 2 & $\begin{array}{l}\text { Recently constincted repository using Monel- } 400 \text { alloy } \\
\text { (experiment was to establish the reproducibility of } \\
\text { the results of experiment 1). }\end{array}$ \\
\hline 3 & $\begin{array}{l}\text { Recently constructed repository subjected to a gamma } \\
\text { radiation field of } \sim 1 \times 10^{5} \mathrm{rad} / \mathrm{h} \text {. }\end{array}$ \\
\hline 4 & Old repository with long-term breach of waste package. \\
\hline 5 & $\begin{array}{l}\text { Old repository with long-term breach of waste package } \\
\text { and extensively altered waste glass, backfill, and } \\
\text { host rock. }\end{array}$ \\
\hline $6^{\mathrm{a}}$ & $\begin{array}{l}\text { Old repository with the waste package recently breached } \\
\text { (unaltered waste glass). }\end{array}$ \\
\hline
\end{tabular}

provided in parametric experiments. While there may be questions regarding particular aspects of the experimental approach, these experiments offer a good starting point to define an experimental strategy to validate PA codes.

2. Tuff Analog - The laboratory analog design as described by Seitz was modified by Bates [27] and applied to the conditions represented by the unsaturated site at Yucca Mountain. The Bates experiments focused on waste form behavior as opposed to the entire system as addressed by Seitz. However, each of the three everits identified in Table 1 exist in the Bates approach.

Bates has developed a test procedure termed "The Unsaturated Test" to study waste form reaction under unsaturated conditions. The Unsaturated Test methodology [27-29] involves periodically dripping groundwater onto a waste form assemblage (waste form plus container metal) and monitoring the changes in solution chemistry and the waste and metal components of the test. The test is performed at $90^{\circ} \mathrm{C}$ in a sturdy metal vessel under rigorously controlled conditions. 
To relate the Unsaturated Test to a more relevant repository environment, Bates used the Seitz analog approach. A tuff core (Fig. 2) was sectioned into two parts, with polished faces and a caviry machined in the bottom section. This cavity has the same dimensions as the inside of the metal vessel used in the Unsaturated Test. This cavity holds the waste/metal assembly with a support arrangement (four support pins that contact the side, but do not touch the bottom, of the rock/ressel) as used in the Unsaturated Test. When the analog test is assembled, the waste package environment is the same as in the Unsaturated Test except the container is made of tuff rock.

Flow of water through the tuff, onto the waste, and out through the rock is accomplished by use of slight positive pressure at the inlet to the tuff core. Iine positive pressure is generated by heating the source vessel to a temperature higher than that of the tuff core. Steam is then forced to the inlet of the tuff core and flow through the core is regulated by controlling the temperature differential. Very clow flow rates can be generated in this fashion.

\section{Apparatus}

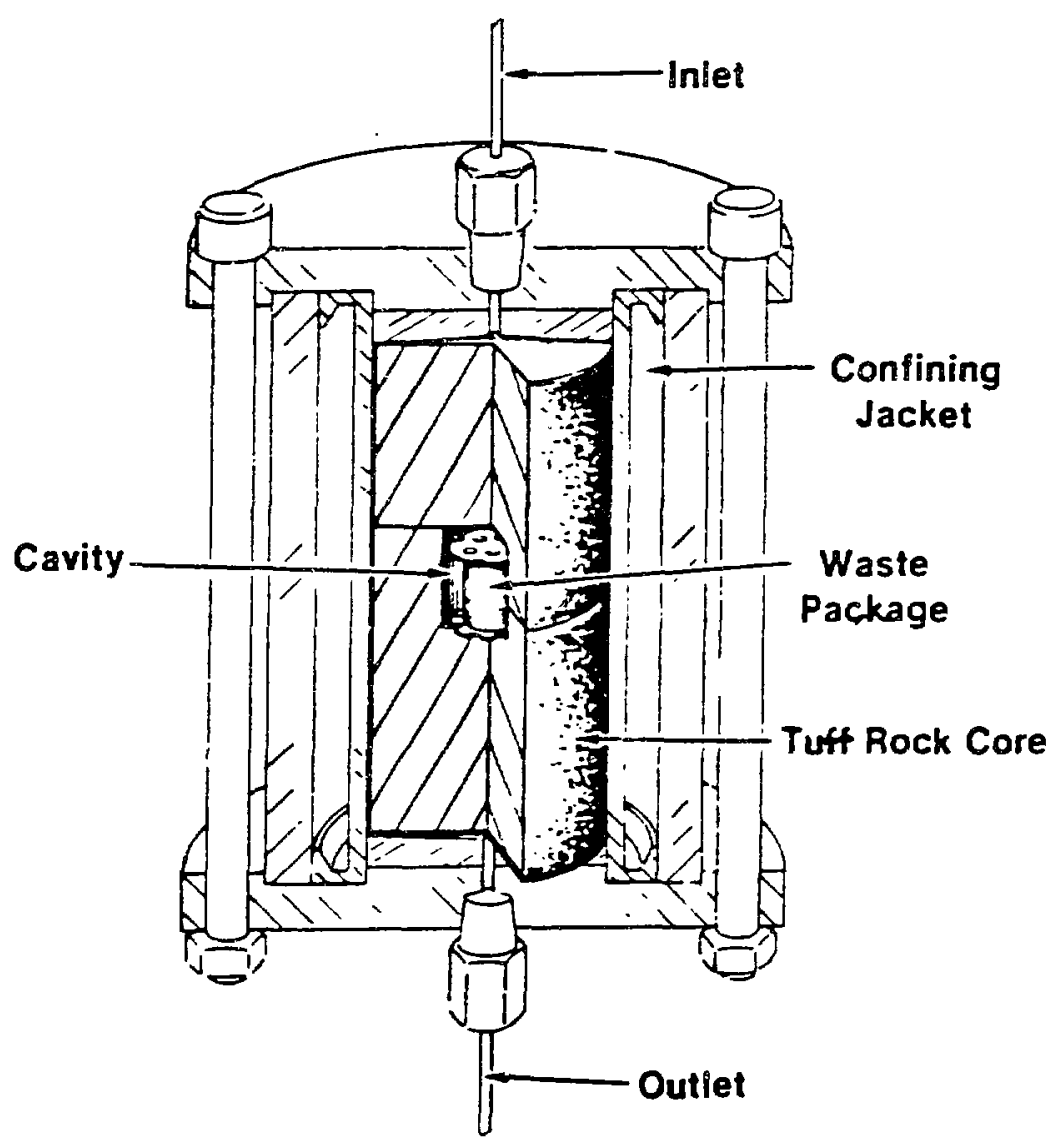

Fig. 2. Diagram of Analog Test Apparatus and Rock Core 
The experiment is run using a water/waste form contact rate (based on surface area of the waste form) similar to that used in the Unsaturated Test $(7.75 \mathrm{~mL} / \mathrm{yr}$ per surface area of $\sim 4 \mathrm{~cm}^{2}$ ).

The main focus of these experiments has been on the waste form. If the same materials interactions, water flow patterns, and radionuclide release from the waste were observed for both the Unsaturated Test and the laboratory analog experiment, it was believed that the Unsaturated Test would have a closer tie to repository performance. The laboratory analog experiment has been run in this Inode using two base glass compositions representative of the Defense Waste Processing Facility and the West Valley Demonstration Project doped with fission product radiotracers $\left({ }^{133} \mathrm{Ba},{ }^{137} \mathrm{Cs},{ }^{152} \mathrm{Eu}\right)$ and the actinide elements $\mathrm{U},{ }^{239} \mathrm{Pu}$, ${ }^{237} \mathrm{~Np}$, and ${ }^{241} \mathrm{Am}$. At this time, three analog experiments have been terminated and the components examined. The longest of the terminated experiments was -1 year. Two experiments are onguing with the longest duration being $\sim 3$ years.

Results from the terminated experiments indicate that the waste form reaction as measured by weight loss and radionuclide release has been similar to that observed in the Unsaturated Test. The water flow patterns and materials interactions are also similar between the two tests. Radionuclide release was detected only on that section of tuff directly below the waste form indicating that the release occurred via water dripping from the waste. The only measurement of radionuclide release made was that of gross release. No distribution measuements were made of radionuclides in the tuff. During operation of the experiment, the effluent was monitored for radionuclide content. No radionuclide relsase from the tuff has been observed.

Bates concluded that the experimental method used resulted in water contact with ihe waste via a dripping or condensation process. The end result was as though water had dripped onto the waste form and dripped off. Bates did, however, note that if the flow through the rock core was increased sufficiently, standing water was found in the bottom of the cavity at the termination of the test. This suggests that either unsaturated (no standing water in the cavity) or saturated conditions (standing water filling the cavity) could be produced using this experimental design.

\section{In-Situ Tests}

In-situ testing has been performed at several sites in various geologic media as a way of providing a method of studying heat transfer, migration of radionuclides, corrosion of candidate container and liner materials, and corrosion of candidate waste forms. These experiments are performed to provide validation of laboratory experiments and models, to investigate potential materials interactions, and to develop in-situ measuring techniques. Such testing programs because of their nature are large undertakings with elaborate test plans, but offer limited flexibility in experimental methods, limited ability to control independent variables, and the ability to alter the experiment after it has begun. The major tests include those at Stripa [54-64] and the Nevada Test Site [79] in granite, WIPP [65-72] and ASSE in salt [80], MOL in clay [74-76], Chalk River in sand [73], and Oak Ridge in shale. 
In most of the experiments, a combination of waste package materials was placed in an actuai repository environment. The waste package components usually included waste form, metals, and backfill material in a constrained arrangement. In some cases the repository action was accelerated by inducing flow or increasing the temperature. Performance of materials was evaluated based on analyse.s of waste package components performed after the tests were completed, on migration of radionuclides through backfill or rock, and on analyses of the groundwater. Unfortunately, the latter measurements are difficult to interpret because of inadequate control of groundwater flow and containment. This drawhack significantly impairs the ability to interpret the results because a complete niass balance requires a measurement of release from the waste plus a description of the remaining materials. In most cases the results observed in the in-situ tests replicate those results observed in more simple laboratory tests (e.g., the effect of backfill in accelerating glass reaction), but in other cases, these have interesting disconnects. Jercinovic [65] reported that basaltic glass reacted in the WIPP environment appeared to react via different processes than glass reacted in a natural brine setting or in simulated experiments. A full understanding of the differences is not available, but this observation stresses the importance in knowing and controlling reaction conditions in doing experiments and interpreting results.

While the results of the in-situ tests may be useful in demonstrating relevance to a repository environment, it is not clear that any additional information is gained that is not available from well-conceived laboratory experiments. In fact, for data interpretation and modeling it is probably better to work with a laboratory type experiment. Because of cost and schedule implications, it makes sense to do laboratory analog experiments before going directly to in-situ experiments.

\section{Repository Systems Simulation Tests in Granite}

An integrated test method has been developed in the European community to study the reaction of glass in a granitic environment [81-82]. A. round robin of the test is in progress, and some results are available [81]. This test is only a partial laboratory analog test, in that only the first two event; are incorporated into the procedure. Two modules are used. In the first module the groundwater is equilibrated, with rock and various backfill components that may be used in the repository, which is assumed to be saturated. The second module contains backfill, waste, and pretreated metal in close contact. The test is a static replacement test whereby an aliquot of solution is removed from second module every two months and replaced by an equivalent amount of water from the first vessel. In this fashion, the solution concentrations can be monitored continuously, but the test components can be investigated only at the termination of the test.

The results of solution analyses indicate that "equilibrium" is reached in both vessels after $\sim 2-4$ months of testing. This means that the $\mathrm{Si}$ concentration in solution is constant. However, the glass is continually reacting as monitored by the release of elements unique to the glass. Radionuclide sorption onto the backfill and metal components in the second vessel can be examined, but flow and radionuclide transport through the granitic rock cannot be 
studiec. The key points from these experiments are that (1) the configuration of rock and backfill in the first module can affect subsequent glass reaction, (2) ihe clays that are used as backfill can either accelerate or depress glass reaction depending on their effect on the $\mathrm{Si}$ corcentration in slie viater, and ' 3 ) except for a few types of backfill material, the glass reaction rates are not mucn different than those observed in a standard MCC-1 leaching test conducted with DIW.

\section{E. Mlaterials Interaction Tests}

There have been many tests conducted that examine in detail factors affecting one of the three main events. Usually these tests have been performed to gain an understanding of the effect of parameters listed in Table 1 on reaction processes. Such tests provide mechanistic insight and reaction trends if done as a function of time. In some cases, the tests incorporate several parameters into the methodology. When this is done the tests are usually conducted to identify which interactions are important for study in more controlled environments. In the following review, those experiments relevant to the proposed tuff site will receive most attention, although other experiments will be described if relevant information exists.

\section{Groundwater Ingress}

The interaction between water and tuff has been the subject of intensive study as a means of defining the near-field waste package environment [83-101] as it will be affected by the emplacement of waste. The most important data that result from groundwater ingress ars (1) the composition of the water that contacts the waste package and (2) the amount of water available for reaction with the waste form and transport of radionuclides from the waste form. In the following discussion, the water composition is treated as the key dependent variable that results from groundwater ingress. The amount of water available for waste form reaction, while important, is treated as an independent variable set by the repository (or test) conditions.

With respect to water composition, factors that have been evaluated include the effect of radiation on the mechanical and chemical properties of rock, the effect of dehydration-rehydration cycles on the hydrologic and chemical properties of rock and associated groundwater, and the development of secondary phases. Factors that need to be considered include the composition of pore water in unsaturated rock and the composition of the water at the repository horizon during passage through the waste package.

Rock/water interaction tests have been done using solid core wafers and crushed rock at temperatures to $250^{\circ} \mathrm{C}$ and with varying $\mathrm{SA} / \mathrm{V}$ ratios. In all of the tests the rock was submerged in water. The purpose of the tests was to determine the type of alteration that may occur to the tuff and groundwater and to provide a test case for the EQ3/6 modeling code. The results indicated that at the lower temperatures $\left(90^{\circ} \mathrm{C}\right)$ the reaction took considerable time to reach equilibrium (after one year equilibrium had not been reached) and that the alteration reactions may have been kinetically inhibited. The most significant compositional changes in the water were a modest increase in $\mathrm{Si}$ concentration reflecting dissolution of tuff and a depletion of calcium, 
magnesium, and carbonate reflecting the precipitation of calcite-type phases. The $\mathrm{pH}$ of the solution and the amount of other anions remained unchanged. The secondary phases that evolved were clays and zeolites. The modeling results were quite successful in matching the data generated experimentally.

In other experiments there appeared to be no effect on the permeability of unfractured rock due to dehydration but there was a decrease in permeability in fractured systems. No effect of radiation on rock properties was observed.

It should be stressed that the above results (radiation and water/rock interaction) wise obtained under saturated conditions. Unsaturated conditions in which $\sim 65 \%$ of the pores are filled with water would accentuate any effects on solution chemistry due to radiation. The radiation effects whicil take place mainly in air would be concentrated in the smaller volumes of water present under unsaturated conditions. Also with smaller volumes of water, any rock/water interactions would be affected due to a markedly increased SA/V ratio. Whether this increased SA/V would affect tuff alteration is not known. It was also noted that cristobalite undergoes a phase transformation at $225^{\circ} \mathrm{C}$ which results in a $5 \%$ volume increase.

Two potential interactions have not been explicitly addressed experimentally. First, during the thermal period the water will be driven from the near-field environment and salts may be deposited due to evaporation and wet/dry cycling. Secondly, when the thermal pulse is reduced and water returns to enter the waste package environment, what will its composition be?

Additionally, the effect of other materials on water chemistry has jet to be addressed. Such materials could include the borehole plug or corroded containers, grout, backfill media, and waste from other waste packages. Possible effects would be to alter the $\mathrm{pH}$ levels of the groundwater as generated by the reaction of water and concrete (potential borehole plug material), which may result in a leaching solution that is potentially bad for glass performance. The ability of the EQ3/6 code to successfully model groundwater ingress when all interactions are included needs to be demonstrated.

The second data need related to groundwater ingress is the amount of water that will enter the waste package. Until the site is characterized, considerable uncertainty will remain in this area. Thus, bounding limits for groundwater ingress are utilized in the curreni scenarios. However, there is no technical justification provided for the limits and listed information needs include a definition and demonstration of processes by which water could actually contact the waste. The range of conditions that are currently considered to be plausible creates difficulty for both modeling and experimental validation. Our suggested approach is to treat the amount of water as an independent variable and to initially address the expected conditions unless there $\cdot$ is strong evidence that the bounding conditions will result in processes that could compromise the integrity of the repository. For groundwater ingress, the expected condition is matrix flow. However, drilling fractures are also considered to be plausible. Our suggested approach is an important simplification because the amount and movement of water will affect the composition of the water, the reaction with the waste form, and the transport of radionuclides. 
It is important to note that even with the expected conditions of matrix flow where the environment would be vapor dominated, the potential for the waste form to sorb water until a liquid water refluxing process can be established and maintained exists [86].

\section{Waste Package Interactions}

In general, studies of waste package interactions have centered around the waste form as the source of radioactivity. Considerably more information is available on glass than spent fuel because glass is the primary waste form for several countries, glass studies can be done using simulated material, and programs to examine the performance of glass in geologic repositories have been in place for longer than spent fuel. Essentially, the glass studies have expanded from simple tests in whic: glass was reacted with deionized water, to integrated tests using various waste package components. Spent fuel tests, however, are still at the stage where the basic processes controlling spent fuel reaction are being identified. Tests of a more integrated nature will become more common as more basic information is assimilated. Glass and spent fuel testing have been done to simulate specific repository sites, but this section will concentrate on conditions relevant to tuff.

A complete review of physical parameters that affect both spent fuel and glass reaction, with special emphasis on the effect of expected unsaturated conditions on waste form degradation modes, is required to adequately develop a validation strategy. The SCP provides a starting point to obtain the needed information. However, the SCP information must be updated to account for new research. Such a review of parameters is beyond the scope of this report; however, reviews of this type have been recently completed that provide the necessary information $[53,102]$. The results from these reviews are used in the following glass and spent fuel sections.

a. Glass - Site-relevant testing has been performed by several laboratories to study both saturated [103-146] and unsaturated [27-47] conditions. The key result from saturated tests is that the glass reaction is dependent upon the concentration of $\mathrm{Si}$ in the leaching solution. Factors that control $\mathrm{Si}$ concentration control the glass reaction. Thus, if secondary phases form that lower the "steady state" Si concentration level from what it would be with only glass present, the reaction rate of the glass is increased as the glass supplies $\mathrm{Si}$ to solution. Such acceleration is seen in the presence of metals that corrode rapidly and form metal silicates, and certain backfill materials that form stable alteration products. If the $\mathrm{Si}$ level in the water is increased, then the glass reaction is retarded. This can happen also with backfill materials depending on their composition. Saturated tests relevant to the tuff repository, however, have shown no effect due to metals and very little effect due to the presence of tuff. The absence of significant interaction arises because the 304L stainless steel used as a reference material is very stable in the J-13 groundwater and because the water used in the tests usually was repository water that had been equilibrated with tuff. No tuff relevant tests have been done with copper-based metals. 
The effect of radiation is to produce radiolysis products in the air which may subsequently dissolve in the water. Examples of radiolysis products include nitric acid and ammonia. The concentration of nitric acid in solution is dependent on dose rate, the volume of air, and the volume of liquid. The effect of an acidified solution on the glass reaction is generally to accelerate the reaction process, and such acceleration has been observed with deionized water as the leachant. However, in saturated experiments relevant to the tuff site, the production of nitric acid was buffered $b_{y}$ carbonate in the groundwater and by leaching of the glass and no dramatic effect was observed. However, these tests. were done using relatively large volumes of water, and more appropriate tests with smaller volumes of water have not been performed.

A key question in performing glass dissolution experiments under saturated conditions is what evidence is required to judge when the longterm glass reaction rate has been achieved, and whether apparent "steady state" solution chemistry is evidence of the long-term rate. To accelerate the advent of the true "steady state," long-term experiments are often done using crushed glass and a large $\mathrm{SA} / \mathrm{V}$ ratic. Even under such ext=eme conditions there is only a hint of the formation of secondary phases that may increase the long-term rate compared with that observed under standard saturated (MCC-1) conditions.

More extensive interactions between the glass and waste package components have been observed under unsaturated conditions because the limited volume of water present rapidly becomes saturated with elements leached from the glass or metal and kinetic inhibitions to phase formation are reduced. Essentially, the reduced volume of water promotes secondary phase formation which in turn controls subsequent reaction. Thus, if stable secondary phases form, they can act as sinks for released elements. The glass reaction in water vapor depends on the relative humidity, temperature, and glass composition. In an unsaturated environment considerable alteration will have occurred to the glass prior to contact by liquid water. Whether radiation is an important parameter in glass reaction due to the possibility of condensing radiolytic products in a small volume water is being investigated.

Tests done with dripping water also magnify the importance of interactions. Depending on the drip or water contact rate, the release may vary by a factor of 40 . This is due to spallation of reacted material from the glass. The presence of sensitized stainless steel in direct contact with the glass can also increase the rate of glass reaction by about a factor of two. This is due to the formation of metal silicate and iron oxyhydroxide phases as both the glass and metal react.

The corrosion products are also important because of their interaction with radionuclides. The increased surface area and chemical nature of these phases sorb radionuclides which affects the total radionuclide inventory available for groundwater transport. The effect of copper-based reaction products on radionuclide sorption has not been investigated. 
The small volume of water present under unsaturated conditions also accentuates the importance of using waste that actually comes from the glass-producing facility or is an exact simulation. In particular, microcomronents of the glass, e.g., $\mathrm{Ci}^{-}, \mathrm{SO}_{4}{ }^{2}$, and $\mathrm{PO}_{4}=$ play an important role in secondary phase formation. Often simulated glasses do not have these components in their formulations.

A submodel to predict the performance of glass in the repository environment is being developed by Bourcier [117-118]. The submodel is based on the EQ3/6 geochemical modeling code which is comprised of a set of programs which predict dissolution and precipitation processes. The rate equation that has been incorporated into EQ3/6 to predict glass dissolution is:

$$
\frac{d C_{i}}{d t}=\frac{A}{V} \nu k_{+}\left(\alpha_{H^{+}}\right)^{n}\left(1-e^{A f i / R T}\right)
$$

where

$$
\begin{aligned}
& \mathrm{A} / \mathrm{V}=\text { surface area over volume }\left(\mathrm{cm}^{-1}\right) \\
& \nu \quad=\text { stoichiometric factor } \\
& \mathrm{k}_{+}=\text {rate constant (muies } / \mathrm{cm}^{2} / \mathrm{sec} \text { ) } \\
& \mathrm{n}=\text { exponent for } \mathrm{pH} \text { dependence of rate } \\
& \text { Aff }=\text { affinity to dissolve (kcals/mole) } \\
& \mathrm{R}=\text { gas constant } \\
& \mathrm{T}=\text { temperature, Kelvins }
\end{aligned}
$$

Output from the submodel is the change in solution composition as a function of time. This is the dependent variable. Input to the. model is the rate constant, the affinity for glass dissolution, the composition and $\mathrm{pH}$ of the water, and several factors related to experimental design. These are the independent variables. It is important to note that the rate constant and the affinity term are developed independently from specific repository conditions or repositoryrelevant tests and are indeed independent variables. The only test specific input required to model glass performance is a description of the solution composition contacting the glass, the $\mathrm{SA} / \mathrm{V}$ ratio, and the composition of the glass (this sets the affinity term). The dependent variable from the groundwater ingress event becomes an independent variable for the glass reaction event.

b. Spent Fuel - Leach tests witk spent fuel have only been done under saturated conditions [147-161]. These tests have been conducted using several different designs (static, intermittent water replacements, flow through, and rocking autoclave) to try and identify and simulate potential interactions. Usually the tests have been done with repository-relevant groundwaters and container 
materials; however, because of the factors noted for saturated glass tests, the metals show little interaction other than sorbing radionuclides. "The relatively large volume of water kinetically inhibits secondary phase formation. The information providea by these tests is usually a description of radionuclide release based on solution composition, but with little certainty that the tests have reached a "sieady state" condition controlled by long-term secondary phase formation.

The physical nature of spent fuel introduces several important concerns that are not relevant for glass. These concerns include the release of volatile species, p-eferential release from grain boundaries, the sensitivity of dissolution to the extent of oxidation of the fuel, different cladding materials in contact with the fuel, and the generation of fines during sample preparation for testing. All of these factors must be taken into account in designing an experiment, but a full understanding of any of the factors is still lacking.

The only results available for studying the reaction of $\mathrm{UO}_{2}$-based waste under unsaturated conditions have been dripping water tests with $\mathrm{UO}_{2}$ pellets [30]. The results obtained in these tests differed significantly from standard leach tests in that secondary phase formation occurred quite readily and the amount of uranium released from the $\mathrm{UO}_{2}$ was closely related to the sequence of phases formed. The initial phase observed was dehydrated schoepite. At this point, there was a pulse of uranium released. Eventually, uranium phases containing cationic components from the groundwater formed and the rate of uranium release decreased. These results reinforce the effect of small volumes of water in concentrating soluble elements and enhancing secondary phase formation and waste form reaction. For $\mathrm{UO}_{2}$, the major cation supplied by the solid is uranium and the groundwater supplies additional elements for phase formation. With glass, the glass controls the secondary phase formation and the water mainily provides a transport medium. While these results are not a substitute for actual tests with spent fuel, they do indicate that the conditions under which a test is performed, i.e., the choice of test parameters, can significantly alter the results.

In both the glass and spent fuel experiments, solutions are routinely analyzed to determine the concentration of elements (radionuclides and matrix formers). Often the solutions are filtered to determine the colloidal fraction present. In general, the transuranic elements have a low $\left(<10^{-6}\right.$ molar) solubility in J-13 groundwater, and in some cases, there is preferential sorption onto container materials or back onto the waste form. The behavior of each radionuclide depends on its chemical form (speciation) in solution. This information is not easily obtained because of limits on experimental techniques and the fact tinat in tuff groundwater, speciation of actinides is not well defined from direct experimental observations, especially under the localized redox conditions that may exist.

As with glass, a submodel to predict the performance of spent fuel based on the EQ3/6 geochemical modeling code is being developed by the YMP $[147,161]$. At this time, the submodel for spent fuel reaction simulates the reaction process by assuming a reaction rate and predicts the sequence of solids that precipitate from solution and the change of solution composition as a 
function of time. At this point in the development, terms to predict the rate and aifinity of spent fuel reaction have not been explicitly incorporated into the model. However, the development of such terms is ongoing and is essential for the independent modeling of the reaction progress. As with glass, the key output from the spent fuel modeling program will be the description of the solution after waste form reaction. The independent variables should be similar to those identified for glass reaction.

\section{Radionuclide Migration}

Processes of radionuclide migration through tuff and methods to monitor such migration have been addressed in experimental or hypothetical systems where no specific provisions for waste package degradation have been incorporated [162-186]. The focus of these previous analyses has been the interaction of radionuclide species with the environment (rock matrix) under given sets of flow conditions and rock properties. Numerous experimental and modeling programs, particularly those being performed by YMP, are currently devoted towards refining and validating these numerical transport models. Concurrently, field-based estimates and laboratory measurements of rock properties crucial to developing coupled hydrological and chemical models of radionuclide transport are also being conducted. It is important to keep in mind that the strength of available models is directly related to the depth of present understanding of the fundamental processes that control the transport of radionuclides. As noted above for example, a key concern with most of the existing models is that they were specifically developed to address radionuclide transport in saturated groundwater systems. Furthermore, the potential effects of waste package components on the subsequent interaction of released radionuclides with the rock matrix have not been adequately treated in the majority of these studies. The admittedly more complicated analogue experiments designed and performed at ANL [7-26, 27-53] have addressed some of these limitations. ANL's laboratory analogue system, which is intermediate between the types of simplified experiments performed to date and the field analogue systems, is one means for validation of advanced radionuclide transport models.

The theory governing the transport of groundwater and dissolved sulutes in saturated media has been described at great lengths in several excellent treatises [e.g., 169, 163, 168; cf. 181, 177]. Two basic processes operate to transport radionuclides in the near-field environment, diffusion and advection. Physical and chemical processes can also act to immobilize radionuclides along their transport paths; these are said to be retardation processes. Finally, it has also been recognized that differential movement and mixing of fluids along groundwater flow paths leads to mechanical dilution of contaminated fluids, a process referred to as dispersion.

In its simplest form, the rate of groundwater flow through a porous media can be determined from Darcy's law:

$$
\mathbf{v}_{\mathbf{x}}=\frac{K \mathrm{dh}}{\epsilon_{\mathrm{p}} \mathrm{dl}}
$$


where $v_{\mathbf{x}}$ is the average linear velocity of groundwater flow, $K$ is the hydraulic conductivity, $\epsilon_{\mathrm{p}}$ is the effective matrix porosity, and $\mathrm{dh} / \mathrm{dl}$ is the hydraulic gradient. Darcy's law is applicable to unsaturated flow except that the hydraulic conductivity, $K$, is a function of the degree of saturation. An equation similar to Eq. 2 can be used to describe fracture flow transport by substituting a fracture porosity term, $\epsilon_{f}$, for the matrix porosity term; flow through a single fracture can also be described by Eq. 2 by eliminating the porosity term. An unreactive radionuclide that is transported by pure advective flow will have the same linear velocity $\left(v_{x}\right)$ as the fluid media.(i.e., ignoring dispersion effects). The mass flux of the dissolved radionuclide from a specified cross sectional area of the flow can be readily computed from Eq. 2 if the concentration of the radionuclide in the fluid is known. Similarly, the flux of radionuclide transported by diffusion can be estimated from Fick's second law if the diffusion coefficient (D) of the radionuclide is known. If diffusion occurs through interconnected water in a porous rock media, the effective diffusion coefficient $\left(D_{\text {eff }}\right)$ will depend on the constrictivity $(\alpha)$ and tortuosity $(\tau)$ of the pores, and the effective porosity $\left(\epsilon_{p}\right)$ in the following manner [178]:

$$
D_{\text {eff }}=\frac{\epsilon_{p} a D}{\tau^{2}}
$$

It is possible (see below) that diffusion through the rock matrix will transverse the direction of advective transport. In this case, matrix diffusion can serve to reduce the flux of advectively transported radionuclides. It must be remembered that, in contrast to advective transport, diffusive transport is predicated on the availability of interconnected fluid in the rock media. In the unsaturated zone, it is uncertain whether such interconnected fluid will be present under post emplacement conditions [e.g., 186, 167, 179, 184].

Retardation reactions will tend to reduce the transport rates of some radionuclides through chemical or biological means. The latter mechanism has not been addressed to any significant degree in the existing literature. Chemical retardation processes include adsorption, cation exchange, and precipitation. The sorption characteristics of the bulk rock media with respect to a specific radionuclide can be described by its distribution coefficient $\left(K_{d}\right)$ :

$$
\mathrm{K}_{\mathrm{d}}=\Sigma \mathbf{f}_{\mathrm{i}} \mathrm{K}_{\mathrm{di}}
$$

.

where $K_{d}$ is the bulk rock distribution :oefficient, $f_{i}$ is the fractional surface area of mineral " $i$ " and $K_{d i}$ is the specific distribution coefficient for the mineral " $i$ ". The use of $K_{d}$ to estimate the proportion of radionuclide immobilized onto the rock surfaces assumes the existence of an adsorption equilibrium. Otherwise, the sorption ratio, $R_{d}$, may be substituted for $K_{d}[183,184,186,164]$. It must be recognized that $K_{d i}$, and hence $K_{d}$, depends not only on the characteristics of the solid but also on the solution chemist:y (e.g., concentration and speciation of radionuclide and $\mathrm{pH}$ ). 
In contrast to sorption, ion exchange and precipitation are "bulk" (as opposed to purely surface) trapping phenomena. In an analogous manner to sorption, however, the ion-exchange characteristics of the rock may be described by the weighted sum of the ion-exchange distribution coefficients of the component minerals. The ion-exchange distribution coefficient significantly depends on the solute concentration of the exchangeable cations in the host minerals, in addition to other factors that also govern sorption. Precipitation usually occurs (note: kinetic infiltrations to precipitation can result in supersaturated solutions) when the solubility limits of secondary phases are attained in the groundwater solution [e.g., 172]. Retardation will result if the secondary phases formed can host radionuclides into their lattice structure, although the secondary phases themselves need not be radionuclide phases. In flowing groundwater solutions, saturation of secondary phases could result from changes in solution composition, most notably that of $\mathrm{pH}$ and redox potential, arising from rock/water reaction.

Quantitative solute transport models in saturated groundwater systems have been developed by coupling the transport equations to the equations governing solute retardation [162-186]. For example, Neretnieks [178] described the average linear velocity of a solute “ $\mathrm{j}$ " $\left(\mathrm{v}_{\mathrm{xj}}\right)$ during fissure flow in crystalline rocks as follows:

$$
v_{x j}=\frac{v_{x}}{1+\Psi K_{d} \rho_{I}\left(1-\epsilon_{f}\right) / \epsilon_{f}}
$$

where $\rho_{\mathrm{r}}$ is the rock density and $\Psi$ is the utilization factor that accounts for the fraction of the rock that is able to equilibrate with the fluid at the fissure (other terms are as defined previously). $\Psi$ depends on the fissure spacing $S$ and the penetration thickness $\eta$ :

$$
\Psi=\frac{2 \pi}{S}
$$

The penetration thickness $\eta$ is defined as:

$$
\eta=\frac{2\left(D_{\text {app }} t\right)^{1 / 2}}{\pi^{1 / 2}}
$$

where $t$ is time and $D_{\text {app }}$ is the apparent diffusivity:

$$
D_{\text {app }}=\frac{D_{\text {eff }}}{K_{d} \rho_{r}}
$$


Equations 5 to 8 can be used to cescribe the average linear velocity of solutes transported by fracture flow through saturated crystalline rocks. Knowledge of $\mathbf{v}_{\mathbf{x}}$, $K_{d}, \rho_{r}, \epsilon_{q}, S$ and $D_{a p p}$ allows prediction of the average linear velocity of solutes at any time during solution flow. If all these parameters are constant, the solute transport rate will decrease, and the penetration thickness will increase with time.

This treatment incorporates loss of solute to the matrix by diffusion and adsorption but dispersion effects have been totally ignored. Also in Eq. 5, no distinction is made between adsorption and ion-exchange. Using the above relationships, Neretnieks [178] set up differential equations describing the conservation of mass during fracture flow and matrix diffusion of radionuclides with additional provision for nuclide decay. For very large fracture spacings (i.e., where matrix diffusion between fractures do not interact), Neretnieks [178] derived the following solution to the coupled differential equations:

$\frac{C_{p}}{C_{0}}=e^{-\lambda t}\left\{\operatorname{erfc}\left[\frac{G}{\left(t-\left(t_{w}+t_{0}\right)\right.}\right]-\operatorname{erfc}\left[\frac{G}{\left[t-\left(t_{w}+t_{0}+\Delta t\right)^{1 / 2}\right.}\right]\right\}$

where

$$
G=\frac{t_{w}\left[D_{\text {eff }}+v_{x} b z / x\right]}{2 b D_{a p p}}
$$

and

$$
\begin{aligned}
& \mathrm{C}_{\mathrm{p}}=\text { radionuclide concentration in the pores, } \\
& \mathrm{C}_{\mathbf{0}}=\text { radionuclide concentration in the incoming solution, } \\
& \lambda=\text { radionuclide decay constant, } \\
& \mathrm{b}=\text { fracture half width, } \\
& \mathbf{x}=\text { distance along fracture, } \\
& \mathrm{z}=\text { distance into matrix from fracture surface, } \\
& \mathrm{t}_{\mathbf{w}}=\text { time required for the water to reach } \mathbf{x} \text {, and } \\
& \mathrm{t}_{\mathbf{0}}=\text { the initial time }
\end{aligned}
$$

Equations 9 and 10 allow calculation of radionuclide concentration at any distance along the fracture flow path, at any depth from the fracture surface, and at any time from initiation of the flow from knowledge of $D_{\text {app }}, K_{d}$, $\rho_{r}, b, \lambda$, and $v_{x}$. Note that because the flow equations for unsaturated fiow are non-linear, they are not subject to a simple solution analogous to Eq. 9 [181]. 
Several simplifying assumptions have been incorporated in the above treatment in order to establish the first order dependence of solute transport rates to the physical and chemical properties of the rock media. Although Neretnieks [178] ignored dispersion effects in his treatment, other workers have subsequently incorporated this effect to the transport equations [e.g., $170,162,171]$. Precipitation and colloid formation were not considered and neither were changes in fracture and matrix porosity that could accompany precipitation. These interactions, if significant, are likely to be most concentrated along the fracture walls, as evidenced by similar interactions in hydrothermal ore deposits. Other potentially important considerations neglected in Neretniek's [178] treatment include: (1) the chemical changes occurring in the transported solution, (2) the chemical and physical (permeability and porosity) heterogeneity of rock matrix, (3) the effects of fracture surface roughness [cf. 165], and (4) the thermal inhomogeneity of the overall system. Models and experiments addressing nonisothermal hydrodynamic conditions are, however, available [e.g., 162, 171, 166, $179,173]$. The main value of Neretniek's [178] treatment, as well as those of subsequent workers [e.g., 170, 181], is that it highlighted the parametric dependence of solute transport in systems of fairly simple geometry. It therefore enabled sensitivity analysis to be performed that allowed Neretnieks [178], for example, to conclude that matrix difrusion can play an important role in retarding radionuclide transport in geologic repositories with fractured heat rock media. It also offered a benchmark for more complicated transport code development and experimental validation [e.g., 181].

In addition to the conceptual models, probable parameter data sets were generated (based on experimental and arbitrary values) in order to perform the sensitivity analysis [e.g., 178, 170]. The validation of these values is a major objective of research being performed by YMP and others. For example, much work has been devoted to defining the distribution coefficient $K_{d}$ appropriate for specific radionuclides (or stand-ins) in tuff [e.g., 181, 182, 176, 183, 164].

Rundberg et al. [181] showed the adequacy of laboratory-measured bulk rock $\mathrm{K}_{\mathrm{d}}$ for modeling experimentally observed breakthrough curves for ${ }^{85} \mathrm{Sr}$ and ${ }^{137} \mathrm{Cs}$ in crystalline rocks. However, questions have been raised concerning derivation of $K_{d}$ from whole rock batch experiments especially where important intrinsic variables (e.g., pH) were not fixed [e.g., 176, 174]. The parameters describing the physical characteristics of fracture and matrix porosity of crystalline rocks is another area of uncertainty. Porosity, constrictiveness, and tortuosity and their variation along fluid flow paths are most difficult to evaluate at present. Unfortunately, these parameters together with $K_{\mathrm{d}}$ (which itself may be spatially variable), determine the magnitude of $D_{\text {app }}$ and hence the extent of matrix storage of radionuclides (Eqs. 3 and 8). Several attempts have been made to measure $\mathcal{L}_{\text {app }}$ directly from experiments [e.g., 141, 175] but the values derived from these measurements are applicable only to the extent that the porosity, constrictivity, tortuosity, and $K_{d}$ values for the crystalline rocks used are representative of that which will be encountered in the repository. Finally, hidden in the saturated hydraulic conductivity term in Eq. 2 are other rock and fluid parameters that also need to be fully characterized:

$$
\mathrm{K}=\kappa \rho_{\mathrm{f}} \mathrm{g} / \boldsymbol{\mu}
$$


where $\kappa$ is the permeatility, $\rho_{\mathrm{f}}$ is the fluid density, $\mathrm{g}$ is the gravitational acceleration, and $\mu$ is the fluid viscosity. As noted above, the primary difficulty in describing the physical properties of both the fluid and the rock arises from the potential spatial variability resulting from thermal, chemical, and stress gradients that are present in most radionuclide release scenarios of interest.

\section{SUMMARY OF IMPORTANT EXPERIMENTAL FACTORS}

\section{A. Water Ingress}

The dependent variable that results from groundwater ingress is the composition of the solution when it contacts the waste package. The chemistry of J-13 water seems relatively invariant as a function of physical parameters that may affect the rock during the isolation and containment periods. As a function of temperature, it takes considerable time to equilibrate the water with the rock, but no dramatic changes in the composition of the water reaching tive borehole boundary are anticipated. However, because secondary phase form stion for either glass or spent fuel is sensitive to water chemistry, it is important to clarify currently undefined factors. Such factors include the effect of site construction and also that of materials present in the borehole other than the waste and container. To provide input to the waste package reaction event, a description of the solution must include the composition with respect to cations, anions, and radionuclides that may be present due to reaction with other waste packages; and the $\mathrm{pH}$ and Eh. A factor further complicating groundwater ingress is sorption of water vapor onto the waste form surface. While the composition of this water would reflect the waste form reaction process and not the water composition in the near field, the important factor is that the water is available to react with the waste and for transport of radionuclides.

\section{B. Waste Package Reaction}

There are two key parameters that affect waste package reaction: (1) the amount of water present, and (2) the "aging" of the waste and container materials. Under saturated conditions, kinetic or nucleation effects appear to retard the attainment of true long-term steady-state reaction rates. This is especially true when the water/waste reaction is initiated in a large volume of water as opposed to attaining saturation through a gradual buildup of water. The effects of potential interactions, e.g., radiation, metal corrosion, etc., are, to an extent, mitigated by the volume of water. Thus, with smaller volumes of water as are present under unsaturated conditions, interactions are accentuated. In addition, the chemical form in which material is released from the waste form and is thereby available for transport varies. In unsaturated conditions, because of wet/dry cycling, material can be released as solids as opposed to actually being dissolved in solution.

The other key parameter, aging, varies with the waste form. Glass will react in humid air by what is essentially a hydration in-situ devitrification process. When liquid water contacts glass, there will likely have been considerable alteration that has occurred that will affect subsequent reaction. Spent fuel will oxidize, thereby becoming more reactive. The rate of oxidation decreases with temperature, but the length of time available for oxidation may offset the lower temperature resulting in fuel with a mixed degree of oxidation. 
Other factors which are secondary, but which should be accounted for are the type and amount of metal corrosion products that have formed prior to containment breach and the interaction of radionuclides with these products, the effect of radiation under unsaturated conditions, and the localized redox ervironment in both saturated and unsaturated conditions.

As with groundwater ingress, the dependent variable that is generated during waste package reaction is the description of the solution as it leaves the waste package. The description of the solution must include the composition with respect to cations, anions, and radionuclides. The form of the radionuclides must also be identified with respect to speciation and whether the radionuclide is truly in solution or is associated with colloidal material.

\section{Radionuclide Transport}

is apparent from previous discussions that most existing models for radionuclide transport have focussed on saturated media. In saturated crystalline rock systems, it is believed that solute transport will be dominated by fracture flow [e.g., 178]. In unsaturated systems with very low flow rates, it is likely that matrix flow will dominate $[135,167]$. Under the latter condition, colloid transport will be primarily by matrix flow or diffusion, depending on the degree of interconnectivity of the pore water and the overall hydrogeological condition (e.g., $\mathrm{D}, \tau, \mathrm{v}_{\mathbf{x j}}$ ) [179]. Nevertheless, it is conceivable that conditions in the unsaturated zone could develop such that fracture flow can occur [185].

In the context of the analog experiments, both saturated and unsaturated conditions can be simulated [27-53]. Use of flow rates expected in the repository [185] is unlikely to yield measurable radionuclide release from the tuff effluent for many elements of interest. This suggests that matrix diffusion and sorption effects may combine to completely retard radionuclide transport through fractured tuff. Breakthrough curves may be experimentally generated by artificially increasing flow rates. Otherwise, characterization of radionuclide penetration depth and distribution on and beneath the fracture surface along the fracture length will provide the only means of monitoring radionuclide transport rates. Nitao [179] pointed out that solute transport in unsaturated systems may be dominated by molecular diffusion along an interconnected fluid phase. If correct, parallel static experiments (i.e., no advective flow) must be performed to parametrically evaluate apparent molecular diffusion rates in such systems. Such experiments should be done as part of the YMP effort to develop models of radionuclide transport. A major difficulty in the previously utilized design of the unsaturated analog experiment is that the water input rate is probably not the same as the flow rate of solution through the tuff [cf. 184]. Furthermore, it is not clear that it is possible to experimentally control the degree of pore saturation in the tuff. As noted earlier, Eq. 2 may be applied to unsaturated flow, but the hydraulic conductivity term, $K$, in this case is a function not only of the saturated hydraulic conductivity but also of the degree of pore saturation (or fracture saturation if fracture flow is considered). A problem that needs to be resolved is how this degree of pore saturation can be controlled or measured, recognizing that in the repository as yell as in the experiment, this parameter may be spatially variable. One possible experimental solution to this problem is to "stabilize" the unsaturated flow rate (as measured from effluent discharge) before radionuclide components are introduced to the input solution. 
Artificially increasing water flow rates in the analog experiments offers the advantage of enabling comparison between laboratory results and advanced models of solute transport (i.e., in saturated systems). Accurate and independent measurement of the hydrological properties of the tuff as well as its adsorption properties (i.e., including measurement of spatial variability of these properties) is imperative for solute transport model validation. Temporal changes in these properties must also be carefully evaluated by runaing several "blank" analog experiments from which hydrological properties may be remeasured at any time during the experimental progress. It is to be expected that tuff, like the waste form, will exhibit aging effects. Such effects can alter the fracture and matrix porosity and sorption characteristics of the tuff. Parallel experiments with and without other waste package components (including the waste form, itself) should also be attempted to examine the influence of these on chemistry of water-tuff interaction and on radionuclide transport. Solutions doped with radionuclides can be used as input solutions in the absence of waste forms. Finally, the form of radionuclide (dissolved, colloids, pseudo-colloids) and its speciation in the solution before and after transport through the tuff should be investigated. Breakthrough curves and speciation characterization of individual radionuclides, and detailed characterization of radionuclide distribution in tuff will enable multiple independent evaluation of transport and retardation mechanisms.

In summary, experimental validation of radionuclide transport modeis in tuff can be accomplished in saturated systems if the following parameters (independent variables) can be specified: (1) solution composition (colloidal fraction), (2) radionuclide speciation, (3) $\mathrm{K}_{\mathrm{d}}$, (4) $\mathrm{D}_{\mathrm{app}},(5) \rho_{\mathrm{r}}$, (6) $\lambda,(7) \mathrm{b}$, (8) $\mathrm{v}_{\mathrm{x}}$, and (9) hydrodynamic dispersion coefficients. The latter parameters, although not discussed at length in this report, may or may not be critical depending on the experimental design. $D_{a p p}$ is a derived paramter that could be either experimentally measured [e.g., 141, 175] or estimated from more fundamental parameters $\left(D, \epsilon_{\mathrm{p}}, \alpha, \tau, K_{\mathrm{d}}, \rho_{\mathrm{r}}\right)$; the same can be said for $K_{\mathrm{d}}$ and $v_{\mathrm{x}}$. In unsaturated systems, an added consideration is the degree of pore or fracture saturation in the tuff. The dependent variable that results from radionuclide transport is the distribution of radionuclides between the solution and the tuff. This can be measured by analysis of both the solution and the tuff.

\section{STRATEGY FOR EXPERIMENTAL VALIDATION OF NEAR-EIELD PERFORMANCE ASSESSMENT}

The basis for near-field performance assessment depends on the coupling of submodels that describe the events/processes of ingress of groundwater, reaction of croundwater with the waste package, and transport of radionuclides through the near-field environment. The important submodel that describes the degradation of the container has not been included in this strategy development because it must be assumed that the container is breached for radionuclides to be released. The effect of container corrosion in the generation of corrosion products should be accounted for in waste package reaction. 
The experimental strategy revolves around (1) identifying those independent variables that affect each of the three processes, (2) identifying the dependent variables that descrive the data needs to assess the repository performance, (3) simplifying the overall approach through the use of bounding assumptions, and (4) establishing whether the dependent and independent variables can be measured/controlled during experimentation.

While submodels that predict the results of any of the three events are still undergoing development, the dependent and independent variables for each of the events/processes can be identified. This has been done in Table 1 and in the preceding discussion. Starting with groundwater ingress, the dependent variable is the description of the groundwater that initially contacts the waste package. This groundwater composition becomes an independent variable for the next process, culminating in the final description of radionuclide distribution. It is clear that the effect of all the independent variables on the resultant processes is not known and it is also clear that a final description of either the materials that will comprise the repository (waste package materials and host roch) or the environment of the waste package and near-field is not available. However, the logic sequence and the identification of needed input and output are well enough established to allow the validation strategy to proceed.

The next step is simplification of the entire process by the restriction or elimination of independent variables for each of the three events. While the ultimate validation process should include all variables that are recognized to influence performance, the validation of 3 ubmodels or validation of the entire system can be done via a sequential process whereby both the models and experiments become more sophisticated with time. The initial simplification process can be based on (1) the assertion that the constraint of a specific variable does not in some way adversely affect the final outcome of repository performance (an adverse affect in this context is to improve repository performance or to alter events to be nonrepresentative of repository performance), or (2) by experimental/modeling necessity.

Examples of experimental necessity could include the elimination of a rnaterial because the material has not yet been described, e.g., container material or borehole plug. Other examples of the elimination of a parameter because the technique for measurement of the parameter needs additional refinement are the measurement of localized Eh environment in the waste package or the determination of radionuclide speciation in repository groundwater. An example of a simplification dictated by modeling necessity could be the exclusion of the effect of corrosion products on radionuclide solubility or speciation. Such a simplification would be required if the model did not contain the required data base to predict the corrosion product effect, or if the necessary subroutines had not been developed.

These types of simplifications can be justified only if it is recognized that validation by comparison with experimental data is constrained to those conditions addressed by the model. For the final validation, simplification can only be done if the effect of the simplification can be shown to not adversely affect repository performance. 
The types of simplifications that are appropriate for initial validation experiments are listed below.

(1) Control the volume of water available for waste form reaction by experimentally establishing either saturated conditions (the waste package inundated with liquid water) or unsaturated conditions (no direct liquid flow pathway from the waste package to the rock).

(2) Fix the composition of the solution contacting the waste package. For example, use J-13 water, or J-13 water equilibrated with tuff at the test temperature.

(3) Maintain the test at a fixed temperature, excluding localized waste form heating.

(4) Eliminate the container material and associated corrosion products.

(5) Induce or accelerate fracture or matrix flow for radionuclide transport by the spatial arrangement of the test components.

(6) Use waste forms (glass or spent fuel) that have the poorest performance with respect to radionuclide release.

(7) Use waste forms that have not been subjected to aging.

(8) Measure only the quantitative release of radionuclides in solution, is opposed to determining the chemical species in solution.

(9) Provide as input to the radionuclide transport only the total radionuclide content of the solution (no speciation or fractionation between colloidal and soluble species).

(10) Assume, on an experimental scale, that the parameters required to model radionuclide transport are constant with respect to samples of tuff taken frum localized areas of the repository horizon. This would allow one rock core to be used in validation testing while another tuff core could be used to measure the required independent variables. An alternate simplification would be to assume that crushed tuff could be used in place of tuff core in both modeling and experimentation.

The above examples recognize that during the initial validation process, simplification and coinpromises may have to be made by both modeling and experimental groups. The extent of simplification can only be ascertained by direct interaction between the two groups. It is suggested that such interaction is now required to continue with any experimental validation.

The fourth element in the development of the experimental strategy, the control/measurement of experimental variables, is discussed in Section VI of this report where several experimental issues are discussed. 


\section{METHODOLOGY DEVELOPMENT FOR LABORATORY VALIDATION TESTING}

\section{A. Testing Methodology, Objective and Background}

As described in Section III, several different experimental configurations have been used to perform laboratory validation experiments. Seitz used a modular approach whereby the three events of groundwater ingress, waste form reaction, and radionuclide transport were partially decoupled. This decoupling allowed for simplified measurement of the dependent variable (solution composition) at each point during the reaction progress, while still maintaining the continuity in groundwater flow. However, the segregation of events may have reduced synergistic effects that would actually occur in the repository. The decoupling of events is a simplification that could be used in initial saturated environment experiments. The methodology and equipment used by Seitz exist and can be easily adapted for use with YMP-specific conditions.

The other testing methodology discussed previousiy was developed by Bates for use in the unsaturated environment with particular emphasis on waste form reaction. The objective of this Subtask is to determine whether the existing methodology can be adapted for use in coupling groundwater ingress and radionuclide transport to waste package reaction without partial decoupling of the events.

\section{B. Experimental Approach}

A schematic representation of the experimental apparatus used to evaluate the coupled experimental validation approach is shown in Fig. 3 . The original system consisted of a tuff core with a diameter of $\sim 4$ " and a length of 8". The core was cut diametrically into two unequal sections and the mating faces of the core sections were polished to an optical finish. A one-step cavity was machined into the bottom section. This cavity was used to contain the waste form (Fig. 3a) which was held between two sections of perforated metal making up the waste package assembly (WPA). The WPA rested on the cavity step making contact with the tuff at four points where the support pins rested on the tuff.

During normal operation, the two sections of tuff were fit together within a flexible confining sleeve that was in turn held in place by an outer metal shell. A tight fit was maintained between the tuff and the flexible sleeve by pressurizing the space between the metal shell and the sleeve. The test was run at $90^{\circ} \mathrm{C}$ with the entire apparatis in an oven.

Water flow was imparted to the system through the inlet opening. The source of water was a water reservoir (not shown) that was connected to the inlet via a narrow ID metal connect tube. The reservoir and the connect tube were heated to a temperature above $100^{\circ} \mathrm{C}$ which forced steam through the connect line to the top of the tuff core. The opening at the top of the core was such that the steam could evenly contact the entire top surface as it condensed. The driving force of water through the tuff was the overpressure generated by heating the water reservoir. Very tight control over the water input rate was maintained by regulating the reservoir temperature between $120^{\circ}$ and $140^{\circ} \mathrm{C}$. 
(a)

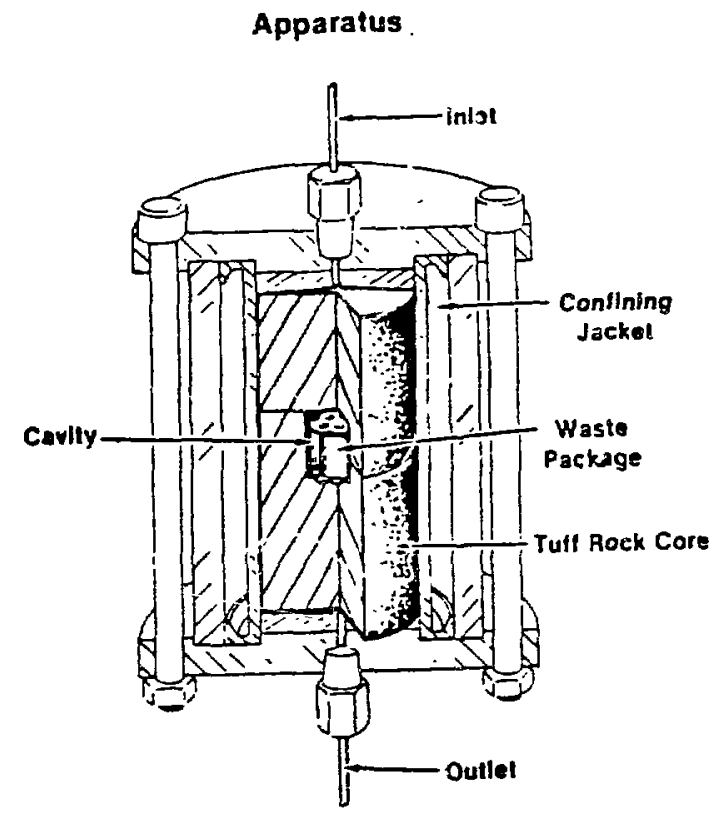

(b)

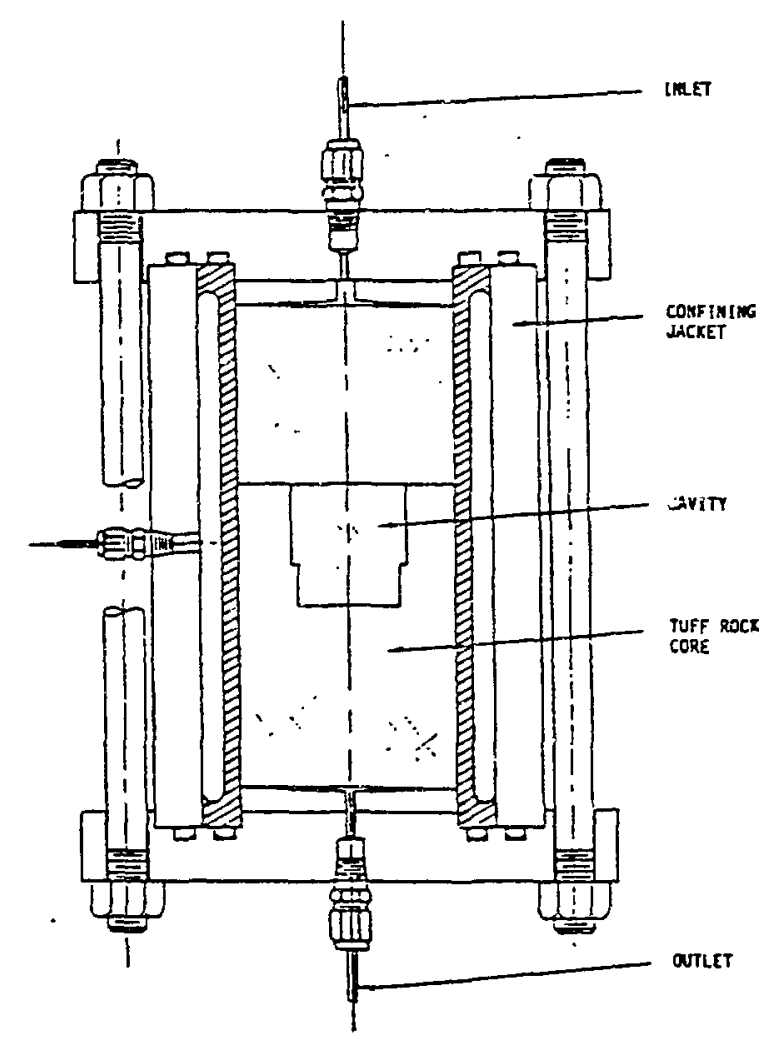

Fig. 3. (a) Representation of the Validation Test Apparatus with Glass as the Waste Form. Note that the waste form does not rest on the bottom of the test cavity but on a shelf situated above the cavity as shown in Fig. 3b, (b) Schematic Drawing of the Validation Test Apparatus without the Waste Form. 
Before the beginning of a test, the tuff core was soaked in J-13 water for several days and weighed immediately before assembling the system. After assembly, the overpressure between the metal shell and the sleeve was increased to $\sim 1400 \mathrm{psi}$ (this was done to ensure that the water that passed through the tuff actually went through the rock core and not along the space between the core and the flexible sleeve), and the temperature in the water reservoir was set nominally at $140^{\circ} \mathrm{C}$.

After about 30 days, water would be detected exiting the system at the outlet line. This water was collected to determine the amount and composition of water that had passed through the system. After the flow rate had stabilized, the temperature of the inlet reservoir was adjusted to obtain the flow rate desired for the particular test in progress.

The test was run for a prescribed period of time, then was terminated by disconnecting the inlet line and reducing the temperature. When the test was disassemiled, the WPA was removed, the amount of water in the cavity measured, and the sections of tuff core were weighed. Typical results were that no liquid water was noted in the cavity, the tuff cores had decreased in weight by several grams, and the WPA had an appearance similar to that noted when water was dripped onto the waste using a different test method [27]. However, in a few cases, 1 to $2 \mathrm{~mL}$ of water was measured in the bottom of the cavity. These results suggest that when the system is run as described, the flow of water through the tuff, into the cavity, and out the outlet line is unsaturated in the sense that the WPA is contacted by cripping water, and no continuous liquid pathways exist between the WPA and the tuff rock. The results also suggest; however, that by increasing the flow rate through the rock, the cavity could become filled with water and a saturated condition could be maintained.

Given the above observations, the initial questions that needed to be addressed to assess whether such a system could be used in a coupled validation test were (1) could the amount of water in the cavity be determined during testing thereby ascertaining whether the system was being run in a saturated or unsatirated mode and (2) could the data required to validate performance models be generated by the test. Through the experiments and projections described below, we have answered these questions.

\section{Degree of Cavity Saturation}

To quantitatively measure the amount of water in the cavity, a series of experiments was performed. Initially, an apparatus was developed to measure the amount of water in the tuff cavity when the bottom tuff section was isolated on a bench top at room temperature. The apparatus that was developed is shown in Fig. 4, and is based on the use of conductivity measurement to determine the depth (volume) of water in the cavity. The method depends on several parameters remaining constant during the testing sequence, e.g., the electrode geometry, the temperature, and the ionic strength of the solution.

Results obtained by measuring the volume of deionized water and $\mathrm{J}-13$ water at $25^{\circ} \mathrm{C}$ and $\mathrm{J}-13$ water at $90^{\circ} \mathrm{C}$ are shown in Fig. 5 . Here it is seen that there is a linear relationship between the conductance and volume of water in the cavity for each condition. It is also evident that, as expected, the conductance increases with temperature and with the ionic streigth of the water. 


\section{$6.3 e$ Tronsformer}

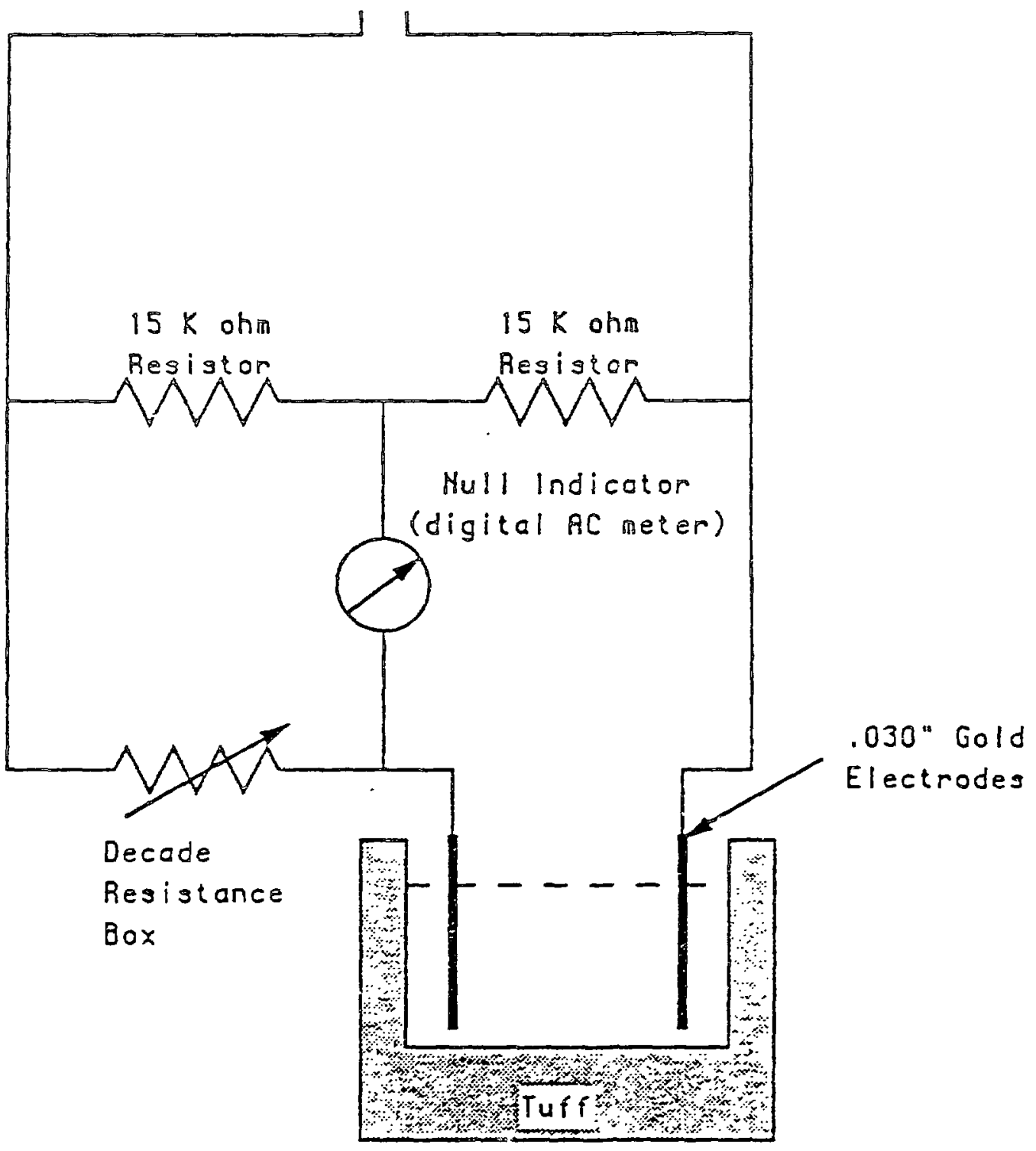

Fig. 4. Schematic Drawing of the Apparatus Used to Meas'ure the Water Volume Collected in the Tuff Cavity 


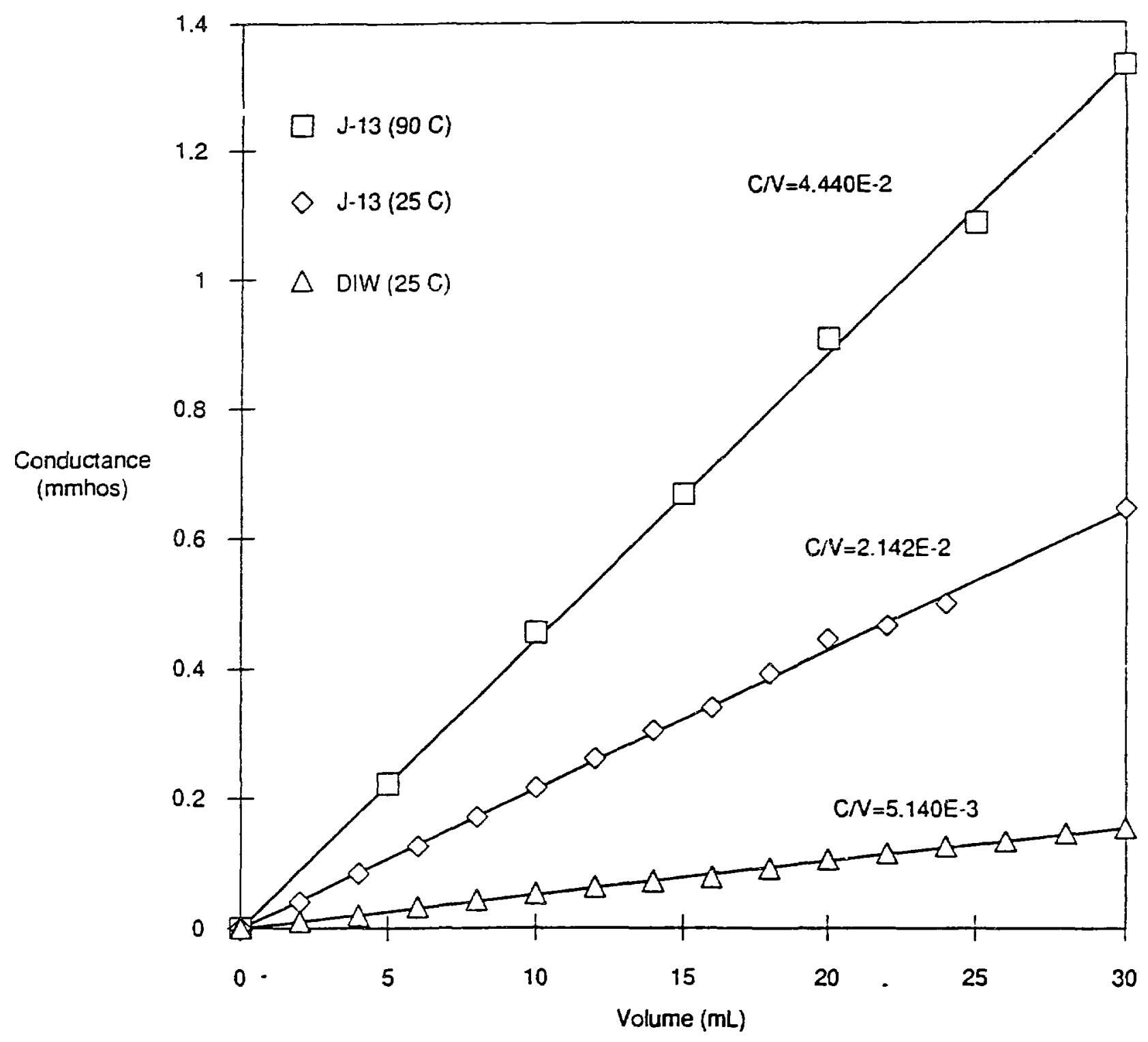

Fig. 5. Measurement of Volume Level in the Tuff Cavity Using Selected Solutions and Temperatures 
To measure the volume of water in the cavity during actual operation of the system at $90^{\circ} \mathrm{C}$ required modification of the test apparatus. The goal was to measure the water volume over an extended period of time to monitor the changes in water level as a function of water reservoir temperature. During the course of the measurements, the electrode geometry must remain constant and the electrode geometry and circuitry must not introduce preferential flow pathways after the system is sealed.

To accomplish this, a shallow, narrow groove was cut diametrically in the polished face of the top section of the tuff. Copper wire of 0.010 " dia was routed in through the inlet port, down opposite sides of the core, and along the narrow groove to the cavity. The wires were sealed in epoxy along the total length of the groove. The gold electrcdes were fastened to the end of the copper lead wires and the epoxy provided adequate support to maintain the electrode location during assembly and operation of the system.

The system was initially set to run at $90^{\circ} \mathrm{C}$ with the water supply at $124^{\circ} \mathrm{C}\left(\mathrm{H}_{2} \mathrm{O}\right.$ pressure $\left.=33 \mathrm{psi}\right)$ and the connect lines at $135^{\circ} \mathrm{C}$. The system was pressurized and run for a period of about two months. For the first 26 days, theie was no significant change in the conductance, and no water was collected at tixe outlet line. Between 26 and 48 days, the conductance rose to a level of 3.3 mmhos and leveled off. The conductance remained level and water began to accumulate in the collection vessel after $\sim 52$ days. After 52 days, the temperature of the water reservoir was reduced to $118^{\circ} \mathrm{C}$ and the conductance began to drop. The experiment was terminated at 66 days before the conductance plot had stabilized. The system was cooled to room temperature and disassembled. At the time of termination the cavity was $\sim 60 \%$ filled with water and contained $12.5 \mathrm{~mL}$. The water was removed from the cavity for later analysis.

To interpret the conductance/time plot for the sealed system, a standard plot (ref. Fig. 6) for the actual water collected in the cavity has to be generated. This water has a higher conductivity than J-13 as indicated by the value obtained after 42 days, 3.3 mmhos, when the cavity was likely filled with water. The higher conductivity results because the tuff core used in the experiment was taken from a block of Topopah Spring outcrop which contained significant amounts of caliche. Although the tuff core had been pretreated by passing water through the core for a period of over one year prior to use in this test, it is likely that salts were still being dissolved as water passed through the tuff. This can only be determined by analysis of the water.

Based on the results of the tests conducted to date, it appears that the water level in the test cavity can be measured (assuming the proper calibration curve can be generated) and the level can be controlled by varying the temperature of the input reservoir. Continued testing would be able to establish this with certainty.

Another goal of the tests was to monitor the rate at which water passed through the tuff as a function of the degree of saturation in the cavity, and as a function of fracture flow in the bottom section of tuff. The need to evaluate fracture flow properties was based on the evaluation of the radionuclide transport literature which indicated that the most rapid and easiest to monitor transport would occur along an open fracture. 


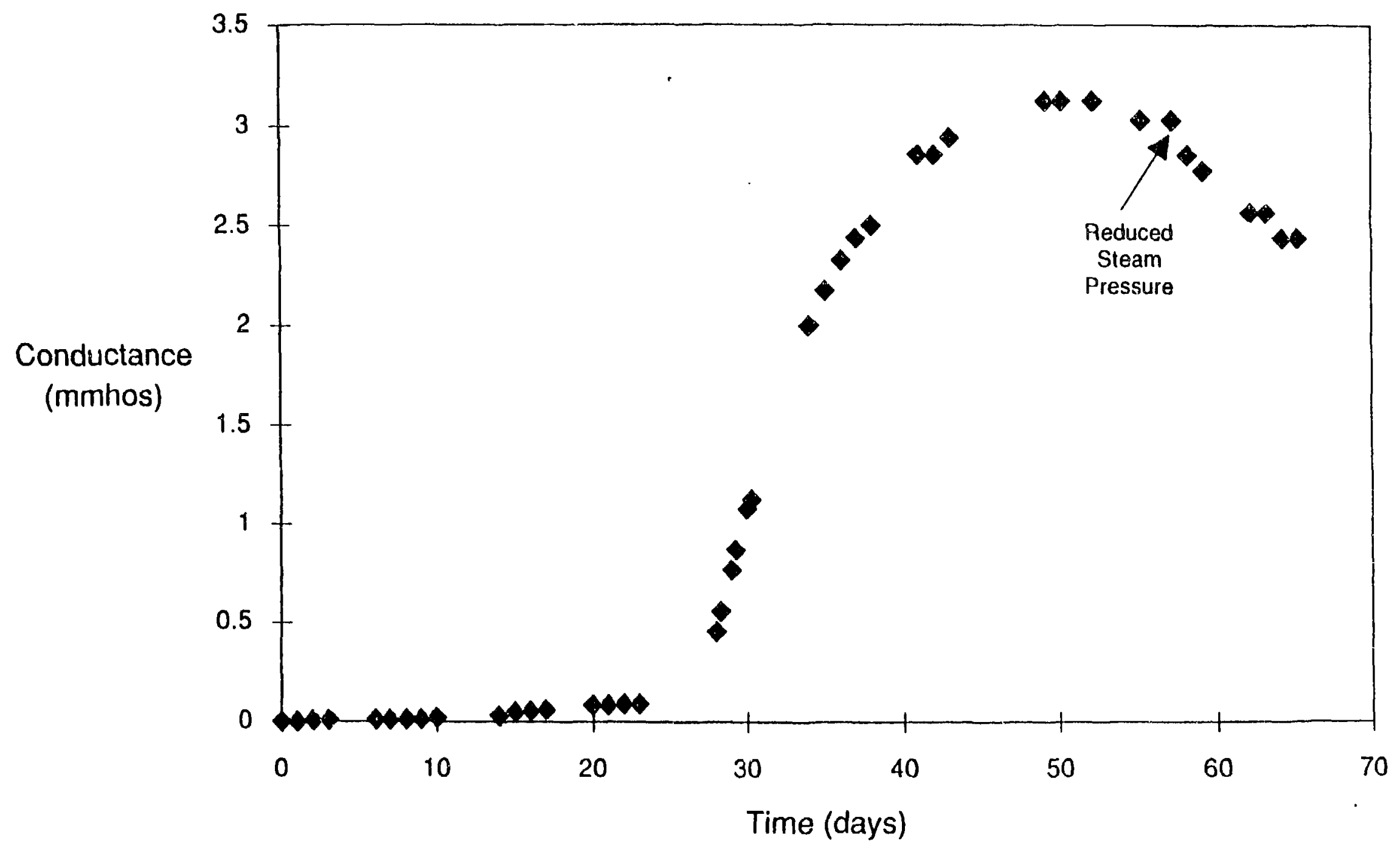

Fig. 6. Measurement of the Conductance of the Water Collected in the Assembled Test Apparatus 
To encourage fracture flow in the bottom section, a core splitter was constructed and tested on several bottom core sections. It was possible to generate a single fracture the length of the bottom core. The width of the fracture could be set by using a gold-lead spacer at the circumference of the section. In this manner it was hoped that after water had entered the test cavity, it would preferentially exit the cavity via the artificial fracture. At this time, a description of the flow properties through the cavity and the tuff (either fracture or intact) has been completed.

\section{Modifications of Apparaius to Allow for Data Measurement}

While we were unable to complete the necessary studies to recommend that this system be used in a coupled validation test, we believe the necessary flow control can be achieved to warrant further study. The following adaptations could be made to simplify the system and allow for measurement of the data required for performance assessment. These modifications are for use in an unsaturated mode.

(1) With the present design, the composition of the water contacting the waste form cannot be measured and effects of other waste package corrosion products or borehole liner materials cannot be assessed. Additionally, the method of contact of water and waste form is uncertain and may not be geometrically consistent or reproducible. While variability of water contact will certainly occur in the repository, it complicates modeling. Thus, one simplification would be to inject the water through an inject port as shown in Fig. $7 \mathrm{~b}$, while still maintaining an overpressure driving force via increased temperature in the water reservoir. In combination with the inject line, a gas sampling line could be constructed to monitor the release of volatile radionuclides as they are released from the waste package and pass through a section of tuff.

Another alternative is shown in Fig. 8a where the water reservoir would be located in the top tuff section with the geometry designed to controi water direction. The reservoir could contain corrosion products and other borehole materials and sampling could be done at the termination of the test or with an in-situ sampling line. Flow would still be induced by the overpressure from the inlet reservoir.

(2) With the present design the composition of the solution as it drips from the waste package and collects in the bottom of the cavity cannot be measured without terminating the test. This limitation could be overcome by adding a cavity sampling access line to perform in-situ monitoring of solution as it collects in the bottom of the cavity (Fig. 7a).

(3) With the present design, the transport of radionuclides through the tuff can only be measured by analyzing the solution that has passed through the tuff and by destructively sectioning and analyzing the tuff core at termination of the experiment. Based on analyses of solutions that have been collected from ongoing tests utilizing radioactive glass (tests in progress for over three years), little if any detection of radionuclides wil! be possible. Neither will it be possible to do an exact analysis of radionuclide distribution throughout the tuff at termination of the test, other than by surface gamma scanning. 


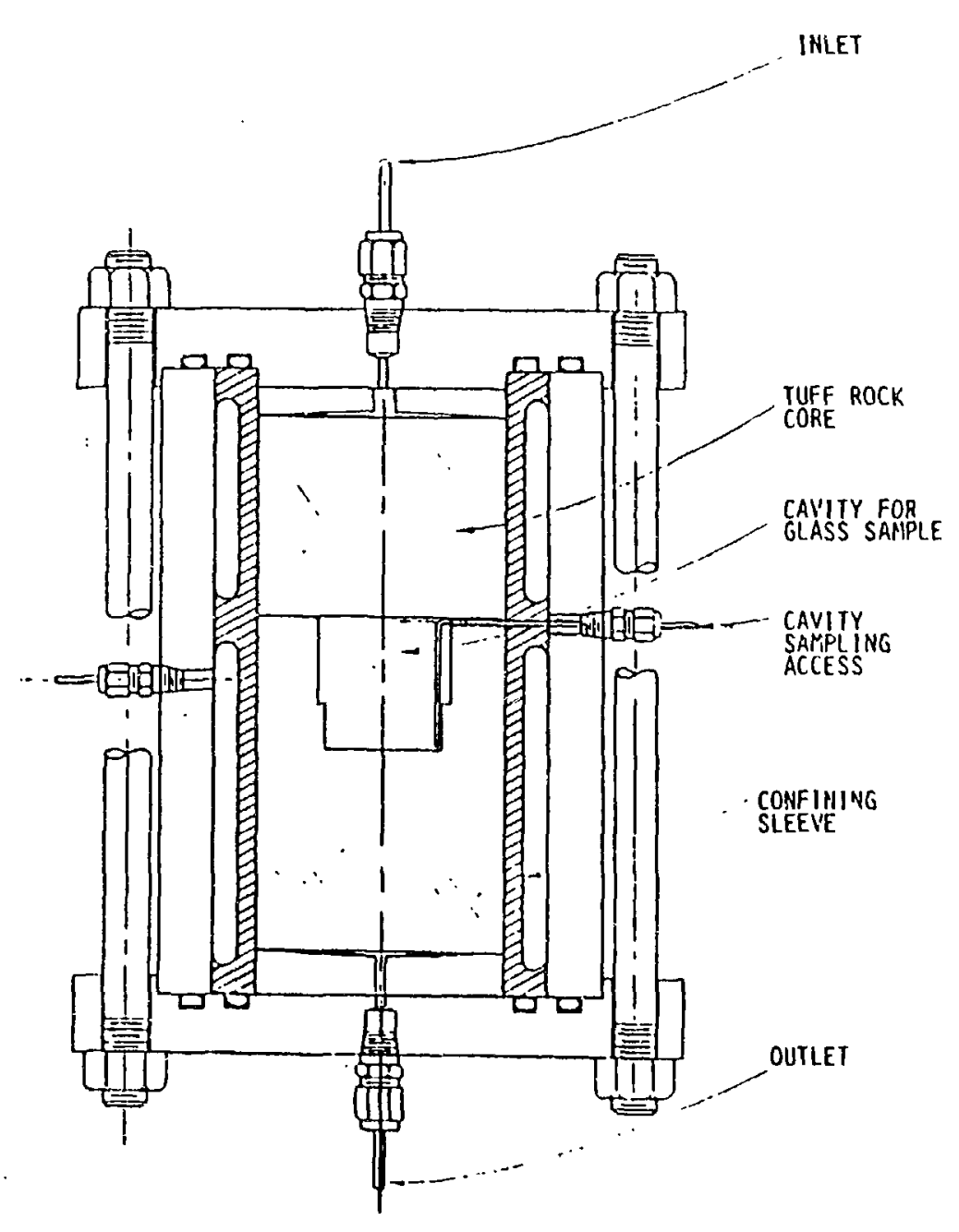

(a)

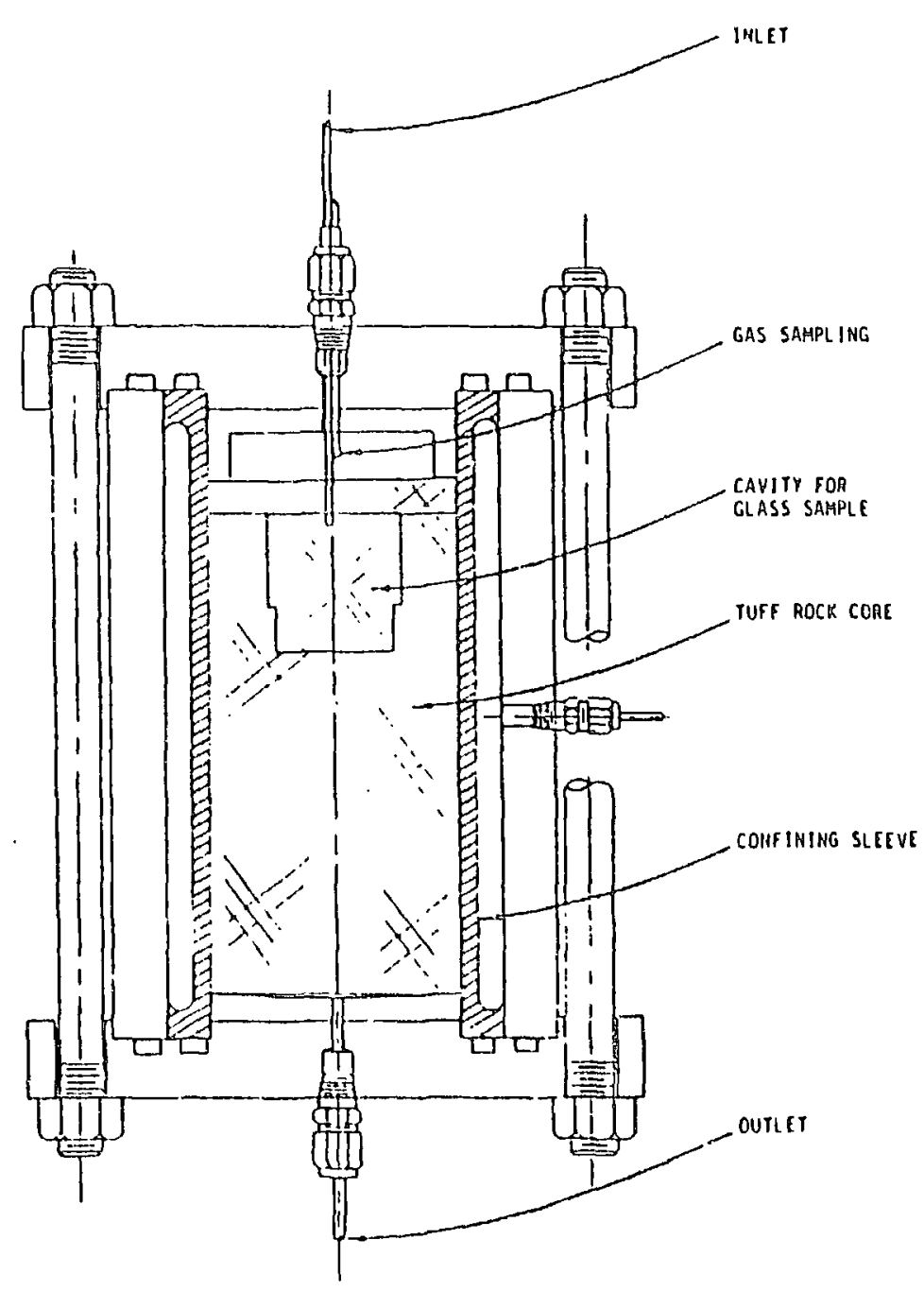

(b)

Fig. 7. Alternative Configurations of the Experimental Validation Apparatus to Allow for (a) Solution Sampling and (b) Controlled Water Input 


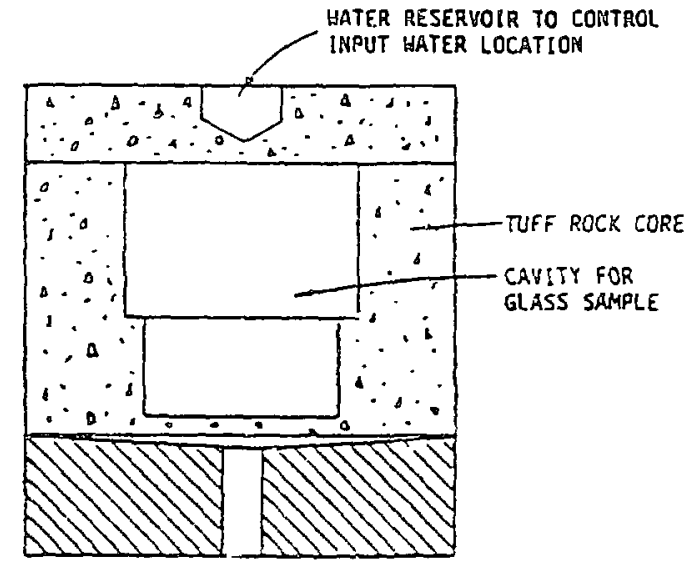

(a)

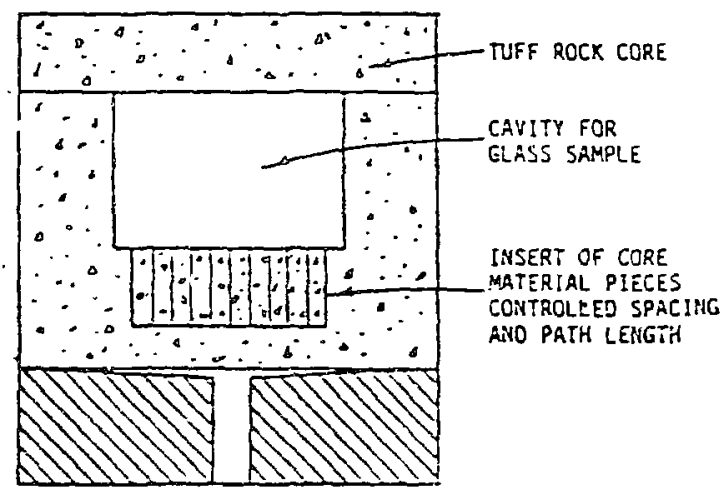

(d)

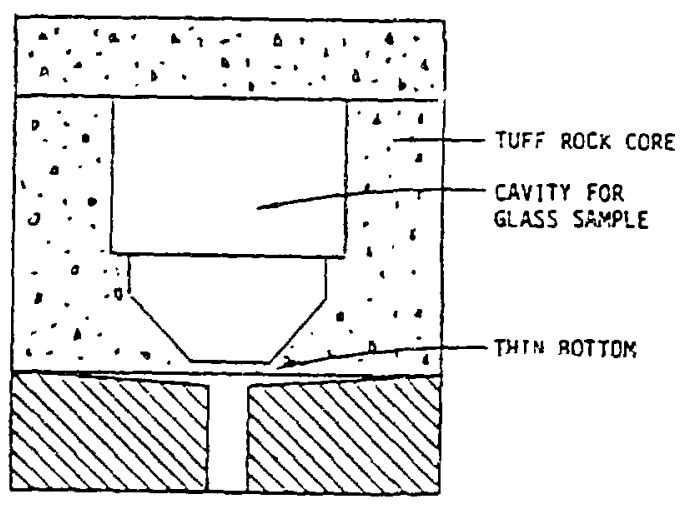

(b)

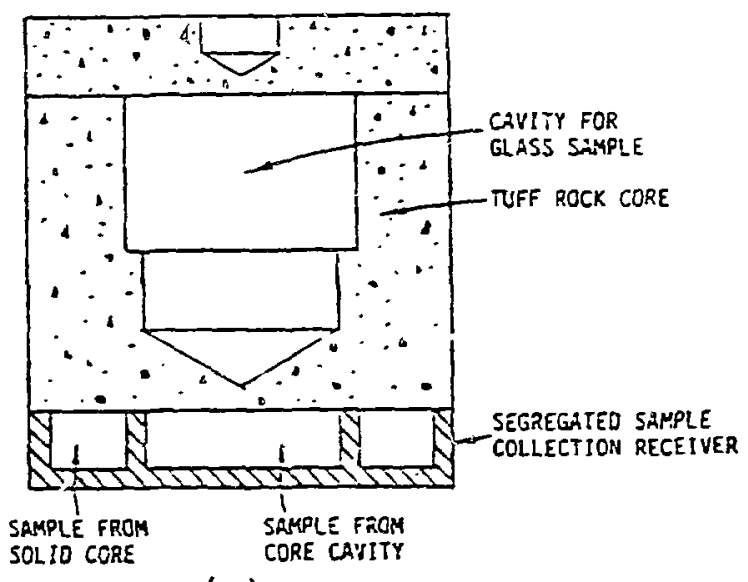

(e)

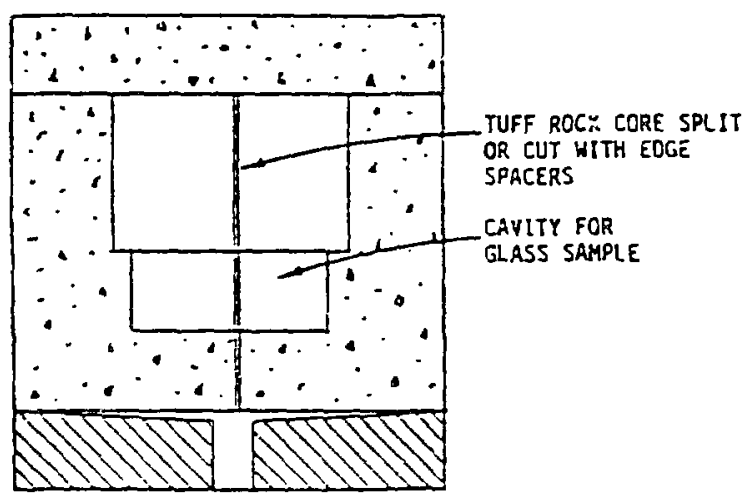

(c)

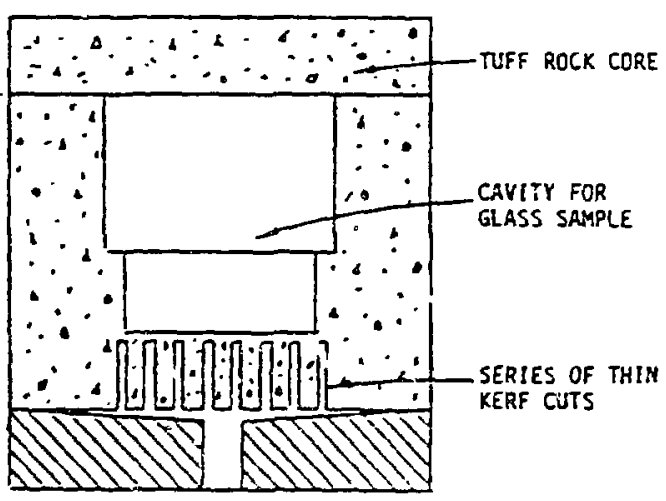

(f)

Fig. 8. Possible Alterations that Could be Made to the Apparatus to Simplify the Measurement of Radionuclide Transport 
To accelerate radionuclide transport, to make measurements of radionuclide distributions easier, and to provide the basic information needed to predict radionuclide transport (see Section V), several modifications are shown in Fig. 8b-f. In Fig. 8b the bottom tuff section below the waste form has a reduced thickness. In Fig. $8 \mathrm{c}$, the rock core is fractured prior to initiation of the test. The spacing of the fracture could be adjusted with spacers to promote fracture flow. The core could easily be separated after the experiment to examine radionuclide distribution. In Fig. $8 \mathrm{~d}$ closed-packed wedges of tuff are placed below the waste form. These wedges could be well characterized prior to emplacement in the test. After the test they could be removed to examine radionuclide distribution. In Fig. $8 \mathrm{e}$ a segregated sample solution collection receiver is shown that could separate solution collected directly below the waste form from that on the periphery of the waste form. In Fig. $8 \mathrm{f}$ a series of kerf cuts are shown in the bottom turf section beneath the waste form. The cuts would promote artificial fracture flow and the remaining tuff could be easily examined for radionuclide distribution.

\section{Use of Modified Unsaturated Test Apparatus for Coupled System Validation}

Arother approach to keeping the three events coupled but allowing for the necessary measurements is shown in Fig. 9. This apparatus has been used in the development of the Unsaturated Test Method [28] for the YMP. During testing with such a system, water is injected through the feedthrough fitting at a set input rate. This rate is chosen to be relevant to the conditions of interest, but is typically $1.8 \mathrm{~mL}$ per year. The composition of the water is established based on the desired preconditioning. The most simple preconditioning would be equilibration with tuff at the test temperature. However, preconditioning could include equilibration with corrosion products or ancillary borehole materials. The preconditioning could be run as a separate batch experiment. This separate preconditioning would represent a simplification in the test methodology, but would allow the composition of the input water to be well established and the water contact rate and direction to be well controlled. The water ingress model would be validated by comparing the composition of the water generated in the separate batch preconditioning test with that predicted by the model.

The second event would occur as the water contacted the waste form. The reaction would take place under unsaturated conditions, as the extent of saturation is controlled by the input rate. The waste form could be either glass or spent fuel and the configuration of the waste package assembly (the combination of waste plus canister/container materials) would be waste dependent. Different configurations have been used for glass [28] or $\mathrm{UO}_{2}[30]$. The extent of reaction would be determined by analysis of the solution that drips from the waste form and collects in the tuff collection cup. Analysis of this solution can be done periodically by opening the test vessel and extracting a portion of the solution for analysis. The test continues simply by closing the vessel and continuing the injection process. If it was desired to analyze the solution that dripped from the waste form prior to contact with tuff, the tuff can be replaced with a metal solution collection cup, or the water can be allowed to drip from 
Test Vessel

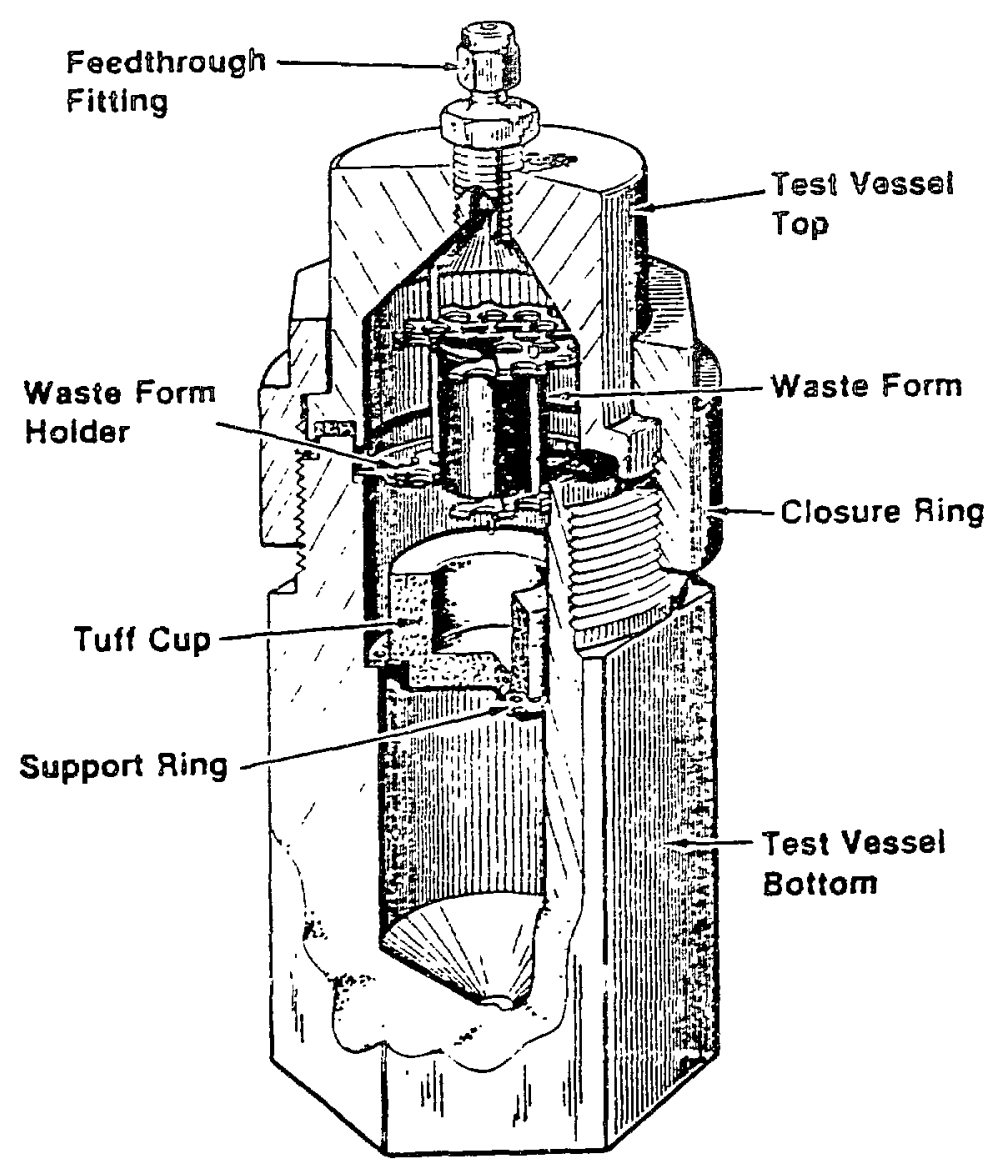

Fig. 9. Drawing of the Apparatus Used in the Unsaturated Test Method

the waste form and collect in the bottom of the vessel. The test has been run in both the tuff cup and no tuff cup collection modes. For purposes of monitoring waste form reaction, it was concluded that the tuff cup provided an unnecessary complication. However, for studying coupled processes of waste form reaction and radionuclide migration, the tuff cup should work well.

The third event in the coupled process, radionuclide migration wouid be evaliated by using the tuff cup in the system. The tuff cup could be characterized prior to insertion in the test to obtain the rock specific data necessary to perform transport modeling. The cup could be subjected to fracturing or controlled configuring to promote desired water flow pathways. Steady-state release from the waste form could be established prior to insertion of the tuff cup, thereby establishing the solution composition prior to contact with the tuff. The tuff cup could be inserted and radionuclide transport monitored by analyzing the solution that collected in the bottom of the test vessel and by 
removing the tuff cup to examine radionuclide distribution. The test could continue for an indefinite period because the liquid that collects in either the tuff cup or the vessel is periodically removed for analysis. Various aspects of radionuclide transport could be evaluated by inserting different tuff cups at different points in the reaction progress.

\section{SUMMARX AND CONCLUSIONS}

The Unsaturated Test Method, with inclusion of the tuff cup, offers an established method to perform a validation test whereby enough simplification has been added to isolate the three events. The test design allows for the collection of data necessary for validation of performance assessment models but still retains enough interaction between the events to be considered a simulation of repository containment. The test has been run with and without a tuff cup while utilizing a glass waste form. Minor adjustments in the test design could be made to perform the test with spent fuel. It is our conclusion that this type of test performed with either glass or spent fuel could provide the necessary information to conduct initial validation of performance assessment code under unsaturated conditions. For saturated systems, the designs used by Seitz or by the RSST programs would be sufficient for preliminary studies. For more advanced validation, whereby the events are coupled without simplifications, the test designs discussed here could provide a starting point for experimentation. 


\section{RREIERTNCES}

1. "Performance Assessment Strategy Plan for the Geologic Repository Program," DOE/RW-0266P (1990).

2. "Performance Assessment Implementation Plan for the Geologic Repository Program," DOE/RW-0267P (1990).

3. M. J. Apted and D. W. Engel, "Mass-Transfer Analysis of Waste Packages Containing Defense Waste Processing Facility Glass as a Waste Form," Proc. of High Level Radioactive Waste Mgmt, Vol. 1, Las Vegas, NV (1990).

4. M. J. Apted, A. M. Liebetrau, and D. W. Engel, "The Analytical Repository Source-Term (AREST) Model: Analysis of Spent Fuel as a Nuclear Waste Form," Pacific Northwest Laboratory report PNL-6347 (1989).

5. W. J. O'Connell, "Status of Integrated Performance Assessment of the Waste Packages and Engineered Barrier System," Prrc. of High Level Radioactive Waste Mgmt, Vol. 1, Las Vegas, NV (1990).

6. C. F. Voss, "A Proposed Methodology for Validating Performance Assessment Models for the DOE Office of Civilian Radioactive Waste Management," Proc. of High Level Radioactive Waste Mgmt, Vol. 1, Las Vegas, NV (1990).

7. M. G. Seitz, D. L. Bowers, T. J. Gerding, and G. F. Vandegrift, "Laboratory Studies of a Breached Nuclear Waste Repository in Basalt," Argonne National Laboratory report ANL-84-16; NUREG/CR-3710 (1984).

8. M. G. Seitz, "Repository-Analog Experiments of Nuclear Waste Leaching and Migration," Internat. Atomic Energy Agency Symp. of the Migration in the Terrestrial Environ. of Long-Lived Radionuclides from the Nuclear Fuel Cycle, IAEA-SM-257, 27-31 July 1981.

9. G. F. Vandegrift, D. L. Bowers, T. J. Gerding, S. M. Fried, C. K. Wilbur, and M. G. Seitz, "The Interaction of Groundwater and Basalt Fissure Surfaces and Its Effect on the Migration of Actinides," in "Geochemical Behavior of Disposed Radioactive Waste," ACS Symp. Ser. 246, Amer. Chem. Soc. (1983).

10. D. L. Bowers, 'T. J. Gerding, S. M. Fried, G. F. Vandegrift, and M. G. Seitz, "Analytical Measurements of Actinide Migration in $a$ Laboratory-Simulated Basalt HLW Repository," the 26th ORNL-DOE Conf. on Analytical Chemistry in Energy Technology, Knoxville, TN, 10-14 October 1983.

11. M. G. Seitz, G. F. Vandegrift, D. L. Bowers, and T. J. Gerding, "Effect of Aged Waste Package and Aged Basalt on Radioelement Release," U.S. Nuclear Regulatory Commission, "NRC Nuclear Waste Geochemistry '83," NUREG/CP-0052 (1984). 
12. M. G. Seitz, P. G. Rickert, S. M. Fried, A. M. Friedman, and

M. J. Steindler," Studies of Nuclear-Waste Migration in Geologic Media," Argonne National Laboratory report ANL-79-30 (1979).

13. M. G. Seitz, R. A. Couture, and M. J. Steindler, "Lt i-Migration Experiments to Determine the Mobility of Radionuclides in Geologic Media," Trans. Am. Nucl. Soc. 32, 385 (1979).

14. M. G. Seitz, P. G. Rickert, S. M. Fried, A. M. Friedman, and M. J. Steindler, "Migration Properties of Some Nuclear Waste Elements in Geologic Media," Nucl. Technol. 44, 284-296 (1979).

15. M. G. Seitz, and M. Seliga, "A Study of the Migration of Leached Radionuclides in a Natural Fissure of Granite Rock," Jarderna Energie 27, 399 (1981).

16. M. G. Seitz, "Repository-Analog Experiments of Nuclear Waste Leaching and Migration," Proc. of Internat. Symp. on the Migration in the Terrestrial Environ. of Long-Lived Radionuclides from the Nuclear Fuel Cycle, IAEA-SM-257.

17. M. J. Steindler et al., "Fuel Cycle Programs Quarterly Progress Report, April-June 1981," Section IV, "Fluids in Rocks," Argonne National Laboratory report ANL-81-53 (1982).

18. M. J. Steindler et al., "Fuel Cycle Programs Quarterly Progress Report, July-Septemiver 1981," Section IV, "Rock-Water Interactions," Argonne National Laboratory report ANL-81-82 (1982).

19. M. J. Steindler et al., "Fuel Cycle Programs Quarterly Progress Report, October-December 1981," Section IV, "Laboratory Analog Program," Argonne National Laboratory report ANL-82-18 (1982).

20. M. J. Steindler et al., "Fuel Cycle Programs Quarterly Progress Report, January-March 1982," Section IV, "Laboratory Analog Program," Argonne National Laboratory report ANL-82-34 (1982).

21. M. J. Steindler et al., "Fuel Cycle Programs Quasterly Progress Report, April-June 1982," Section IV, "Laboratory Analog Program," Argonne National Laboratory report ANL-82-58 (1982).

22. M. J. Steindler et al., "Fuel Cycle Programs Quarterly Progress Report, July-September 1982," Section III, "Laboratory Analog Program," Argonne National Laboratory report ANL-82-78 (1983).

23. M. J. Steindler et al., "Fuel Cycle Programs Quarterly Progress Report, October-December 1982," Section V, "Laboratory Analog Program," Argonne National Laboratory report ANL-83-19 (1983).

24. M. J. Steindler et al., "Fuel Cycle Programs Quarterly Progress Report, January-March 1983," Section III, "Laboratory Analog Program," Argonne National Laboratory report ANL-83-68 (1984). 
25. M. J. Steindler et al., "Fuel Cycle Programs Quarterly Progress Report, April-June 1983," Section III, "Laboratory Analog Program," Argonne National Laboratory report ANL-83-78 (1984).

26. M. J. Steindler et al., "Fuel Cycle Programs Quarterly Progress Report, July-September 1983," Section III, "Laboratory Analog Program," Argonne National Laboratory report ANL-83-88 (1984).

27. J. K. Bates and T. J. Gerding, "NNWSI Dhase II Materials Interaction Test Procedure and Preliminary Results," Argonne National Laboratory report ANL-84-81 (1985).

28. J. Bates and T. Gerding, "One-Year Results of the NNWSI Unsaturated Test Procedure: SRL 165 Glass Application," Argonne National Laboratory report ANL-85-41 (1986).

29. J. Bates and T. Gerding, "Application of the NNWSI Unsaturated Test Method to Actinide Doped SRL 165 Type Glass," Argonne National Laboratory report ANL-89-24 (1990).

30. J. K. Bates, T. J. Gerding, and E. Veleckis, "Repository Relevant Testing Applied to the Yucca Mountain Project," Amer. Chem. Soc. Meeting, Dallas, TX, April 9-14, 1989.

31. J. Bates and T. Gerding, "The Performance of Actinide-Containing SRL-165 Type Glass in Unsaturated Conditions," Mater. Res. Soc. Symp. Proc. 112, 651-662 (1987).

32. J. K. bates and T. J. Gerding, "NNWSI Waste Form Test Method for Unsaturated Disposal Conditions," Lawrence Livermore National Laboratory report UCRL-15723 (1985).

33. J. K. Bates and T. J. Gerding, "NNWSI Waste Form Test Method for Unsaturated Disposal Conditions," Proc. of Waste Management '85, Tucson, AZ, March 24-28, 1985, Volume 1: High-Level Waste, pp. 459-465 (1985).

34. J. K. Bates and T. J. Gerding, "NNWSI Waste Form Performance Test Development," Mater. Res. Soc. Symp. Proc. 44, 295-302 (1985).

35. M. J. Steindler et al., "Nuclear Technology Programs Quarterly Progress Report, April-June 1984," Argonne National Laboratory report ANL-84-57 (1985).

36. M. J. Steindler et al., "Nuclear Technology Programs Quarterly Progress Report, July-September 1984," Argonne National Laboratory report ANL-84-91 (1985).

37. J. K. Bates, T. J. Gerding, T. A. Abrajano, Jr., and W. L. Ebert, "NNWSI Waste Form Testing at Argonne National Laboratory, Semiannual Report, July-December 1985," Lawrence Livermore National Laboratory report UCRL-15801 (1986). 
38. J. Bates, T. Gerding, T. Abrajano, and W. Ebert, "NNWSI Waste Form Testing at Argonne National Laboratory, Semiannua! Report, JanuaryJune 1986," Lawrence Livermore National Laboratory report UCRL-15801-86-1 (1987).

39. J. Bates, T. Gerding, T. Abrajano, W. Ebert, and J. Mazer, "NNWSI Waste Form Testing at Argonne National Laboratory: Semiannual Report, July-December 1986," Lawrence Livermore National Laboratory report UCRL-15801-86-2 (1988).

40. J. Bates, T. Gerding, T. Abrajano, W. Ebert, and J. Mazer, "NNWSI Waste Form Testing at Argonne Natinnal Laboratory, Semiannual Report, January-June 1987," Lawrence Livermore National Laboratory report UCRL-20160-87-1 (1988).

41. J. Bates, T. Gerding, W. Ebert, J. Mazer, and B. Biwer, "NNWSI Waste Form Testing at Argonne National Laboratory, Semiannual Report, JulyDecember 1987," Lawrence Livermore National Laboratory report UCRL-21060-87-2 (1988).

42. J. Bates, T. Gerding, W. Ebert, J. Mazer, and B. Biwer, "NNWSI Waste Form Testing at Argonne National Laboratory, Seiniannual Report, January-June 1988," Argonne National Laboratory report UCRL-21060-88-1 (1990).

43. J. K. Bates, L. J. Jardine, and M. J. Steindler, "Hydration Aging of Nuclear Waste Glass," Science 218, 51-54 (1982).

44. J. K. Bates, M. J Steindler, B. S. Tani, and F. Purcell, "The Hydration Alteration of a Commercial Nuclear Waste Glass,” Chem. Geol. 51, 79-87 (1985).

45. J. K. Bates, L. J. Jardine, and M. J. Steinuler, "The Hydration Process of Nuclear Waste Glass: An Interim Report," Argonne National Laboratory report ANL-82-11 (1982).

46. T. A. Abrajano, C. D. Byers, and J. K. Bates, "Aqueous Corrosion of Natural and Nuclear Waste Glasses I: Comparative Rates of Hydration in Liquid and Vapor Experiments of Elevated Temperatures," J. Non-Crystal. Sol. 84, 251-257 (1986).

47. J. K. Bates and M. J. Steindler, "Alteration of Nuclear Waste Glass by Hydratioil," Mater. Res. Soc. Symp. Proc. 15, 183-190 (1983).

48. J. K. Bates, M. J. Steindler, and P. L. McDaniel, "Hydration of Stressed Nuclear Waste Glass," Mater. Lett. 2(4A), 296-300 (1984).

49. J. K. Bates and V. M. Oversby, "The Behavior of Actinide-Containing Glasses during Gamma Irradiation in a Saturated Tuff Environment," Mater. Res. Soc. Symp. Proc. 44, 257-264 (1985).

50. J. K. Bates, D. F. Fischer, and T. J. Gerding, "The Reaction of Glass during Gamma Irradiation in a Saturated Tuff Environment, P'art 1: SRI, 165 Glass," Argonne National Laboratory report ANL-85-62 (1986). 
51. J. Bates, T. Gerding, D. Fischer, and W. Ebert, "The Reaction of Glass in a Gamma Irradiated Saturated Tuff Environment: Part II. Data Package for ATM- 1 c and ATM-8 Glass," Lawrence Livermore National Laboratory report UCRL-15991 (1987).

52. J. Bates, W. Ebert, D. Fischer, and T. Gerding, "The Reaction of Reference Commercial Nuclear Waste Glasses During Gamma Irradiation in a Saturated Tuff Environment," J. Mater. Res. 3(3), 576-597 (1988).

53. J. K. Bates ê al., "Critical Review of Parameters Affecting Glass Reaction in an Unsaturated Environment," submitted tu DOE-HQ/DP (1989).

54. D. E. Clark, B. F. Zhu, R. S. Robinson, and G. G. Wicks, "Preliminary Report on a Glass Burial Experiment in Granite," Adv. in Ceram. 8, 324-336 (1984).

55. D. E. Clark, B. F. Zhu, L. L. Hench, G. G. Wicks, and L. Werme, "An Evaluation of Six-Month Burial Data from Stripa," Rivista della Staz. Sper. Vetro. n5, 185-195 (1984).

56. L. L. Hench, B. F. Zhu, A. R. Lodding, and L. Werme, "Stripa Burial: Time Dependence of Leaching," Adv. in Ceram. 20, 583-590 (1986).

57. L. L. Hench, A. Lodding, and L. O. Werme, "Analysis of One-Year In-Situ Burial of Nuclear Waste Glasses in Stripa." Adv. in Ceram. 8, 310-323 (1984).

58. L. L. Hench, L. O. Werme, and A. Lodding, "Burial Effects on Nuclear Waste Glass," Mater. Res. Soc. Symp. Proc. 11, 153-162 (1982).

59. A. Lodding, E. U. Engstrom, D. E. Clark, L. O. Werme, and G. G. Wicks, "SIMS Analysis of Leached Layers Formed on SRL Glasses During Burial," Adv. in Ceram. 20, 567-581 (1987).

60. L. O. Werme, L. L. Hench, and A. Lodding, "Nuclear Waste Glass Interfaces After 1 Year Burial in Stripa," Mater. Res. Soc. Symp. Proc. 44, 37-44 (1985).

61. B. F. Zhu, D. E. Clark, L. L. Hench, G. G. Wicks, and L. Werme, "One-Year Leaching of Three SRL Glasses in Granite," Mater. Res. Soc. Symp. Proc. 44, 187-194 (1981).

62. B. F. Zhu, D. E. Clark, L. L. Hench, and G. G. Wicks, "Leaching Behavior of Nuclear Waste Glass Heterogeneities," J. Non-Cryst. Sol. 80, 324-334 (1986).

63. B. F. Zhu, D. E. Clark, A. Lodding, and G. G. Wicks, "Two-Year Leaching Behavior of Three SRL Nuclear Waste Glasses in Granite," Adv. in Ceram. 20, 591-599 (1987). 
64. R. K. Zoitos, D. E. Clark, A. R. Lodding, and G. G. Wicks, "Correlation of Laboratory and Stripa Field Leaching Studies," Mater. Res. Soc. Symp. Proc. 127, 145-152 (1988).

65. M. J. Jercinovic and R. C. Ewing, "Observations of Glasses Reacted in WIPP," presented at the American Ceramic Society Meeting, In dianapolis, IN, April 1989.

66. M. A. Molecke and N. R. Sorensen, "Retrieval and Analysis of Simulated Defense HLW Package Experiments at the WIPP," Mater. Res. Soc. Symp. Proc. 127, 653-660 (1988).

67. M. A. Molteke, "Overview of Waste Package Performance Experiments in WIPP," Adv. in Ceram. 20, 99 (1986).

68. M. A. Molecke and G. G. Wicks, "Test Plan: WIPP Materials Interface Interactions Test [MIIT]," Sandia N'ational Laboratories, Aibuquerque, NM (1986).

69. W. G. Ramsey and G. G. Wicks, "Leaching of SRP Waste Glass in Brine: Laboratory Support of the MIIT Program," presented at the American Ceramic Society Meeting, Indianapolis, IN, April 1989.

70. G. G. Wieks, M. E. Wienle, and M. A. Molecke, "WIPP/SRL In-Situ Tests--Part II: Pictorial History of MIIT and Final MIIT Matrices, Assemblies, and Sample Listings," Savannah River Laboratory report DP-1733 (1987).

71. G. G. Wicks and M. A. Molecke, "WIPP/SRL In-Situ Testing Program," Adv. in Ceram. 20, 657-667 (1987).

72. G. G. Wicks and M. A. Molecke, "WIPP/SRL In-Situ Testing Program--An April 1987 Updated," Savannah River Laboratory report DP-MS-87-4 (1987).

73. J. C. Tait, W. H. Hocking, J. S. Betteridge, and G. Bart, "Field Burial Results and SIMS Analysis of the Chalk River Glass Blocks," Adv. in Ceram. 20, 559-566 (1986).

74. M. Put, M. Monsecour, A. Fonteyne, H. Yoshida, and P. De Regge, "Ir Situ Migration Experiments in the Boom Clay at Mol; Experimental Method and Preliminary Results," Mater. Res. Soc. Symp. Proc. 127, 621-628 (1988).

75. P. Van Isegham, R. DeBatist, and L. Wei-Yin, "The Interaction between Nuclear Waste Glasses and Clay," Adv. in Ceram. 20, 627-638 (1986).

76. P. Van Isegham, W. Timmermans, W. Debruyn, J. Dresselaers, and B. Neerdael, "In-Situ Testing of Nuclear Waste Forms in an Underground Laboratory in Clay," Adv. in Ceram. 20, 649-656 (1986).

77. R. G. Newton, "Summary of the Progress of the Ballidon Glass Burial Experiment," Glass Technol. 22(1) (1981). 
78. R. G. Newton, "Ballidon Glass Burial Experiment," Glass Technol. 26(6) (1985).

79. W. C. Patrick, "Spent Fuel Test-Cliniax: An Evaluation of the Technical Feasibility of Geologic Storage of Spent Nuclear Fuel in Granite. Executive Summary of Final Reports," Lawrence Livermore National Laboratory report UCRL-53762 (1986).

80. T. Rothfuchs, K. Wieczorek, E. G. McNulty, S. K. Gupta, and D. Clark, "The Brine Migration Test - A Nuclear Waste Repository Simulation Experiments at the ASSE Salt Mine - Federal Republic of Germany," Mater. Res. Soc. Symp. Proc. 127, 613-620 (1988).

81. J. L. Dussossory, E. Vernaz, H. Charpentier, and P. Juliet, "R.S.S.T. in Granite: Additional Tests at CEN-Vabiho," presented at the Workshop on Testing of High Level Waste Forms under Repository Conditions in Cadarache, France, October, 1988.

82. J. L. Nogues, E. Vernaz, N. Jacquet-Francillon, and S. Pasquini, "Interaction between a Nuclear Glass and Near-Field Materials in Various Rigs Simulating a Geologic Repository," presented at the Seminaire sur les Dechets Radioactis, Julich, June 10-14, 1985.

83. T. Abrajano, J. Bates, W. Ebert, and T. Gerding, "The Effects of Gamma Radiation on Groundwater Chemistry and Glass Leaching as Related to the NNWSI Repository Site," Lawrence Livermore National Laboratory report UCRL-15825 (1986).

84. J. Byerlee, C. Morrow, and D. Moore, "Permeability and Pore-Fluid Chemistry of the Bullfrog Tuff in a Temperature Gradient: Summary of Results," U.S. Geol. Surv. Open-File Report 83-475; Lawrence Livermore National Laboratory report UCRL-15790 (1983).

85. J. Delany, "Reaction of Topopah Spring Tuff with J-13 Water: A Geochemical Modeling Approach Using the EQ3/6 Reaction Path Code," Lawrence Livermore National Laboratory report UCRL-53631 (1985).

86. W. L. Ebert and J. K. Bates, "The Reaction of Synthetic Nuclear Waste Glass in Steam and Hydrothermal Solution," Mat. Res. Soc. Symp. Proc. Vol. 176, 339-346 (1990.

87. W. Glassley, "Reference Waste Package Environment Report," Lawrence Livermore National Laboratory report UCRL-53726 (1986).

88. K. G. Knauss, "Petrologic and Geoshemical Characterization of the Bullfrog Member of the Crater Flat Tuff: Outcrop Samples Used in Waste Package Experiments," Lawrence Livermore National Iaboratory report UCRL-53470 (1983).

89. K. Knauss, "Hydrothermal Interaction Studies of Bullfrog Mer ber Tuff Core Wafers in J-13 Water at $150^{\circ} \mathrm{C}$ Quantitative Analyses of Aqueous and Solid Phases," Lawrence Livermore National Laboratory report UCRL-53521 (1984). 
90. K. Knauss, W. Beiriger, and D. Peifer, "Hydrothermal Interaction of Crushed Topopah Spring Tuff and J-13 Water at $90^{\circ} \mathrm{C}, 150^{\circ} \mathrm{C}$, and $250^{\circ} \mathrm{C}$ Using Dickson-Type Gold Bag Rocking Autoclaves," Lawrence Livermore National Laboratory report UCRL-53630 (1985).

91. K. Knauss, W. Beiriger, D. Peifer, and A. Piwinskii, "Hydrothermal Interaction of Solid Wafers of Topopah Spring Tuff with J-13 Water and Distilled Water at $90^{\circ}, 150^{\circ}$, and $250^{\circ} \mathrm{C}$ Using Dickson-Type, Gold-Bag Rocking Autoclaves," Lawrence Livermore National Laboratory report UCRL-53645 (1985).

92. K. Knauss and D. Peifer, "Reaction of Vitric Topopah Spring Tuff and J-13 Ground Water Under Hydrothermal Conditions Using Dickson-Type, Gold-Bag Rocking Autoclaves," Lawrence Livermore National Laboratory report UCRL-537\%5 (1986).

93. K. G. Knauss, "Zeolitization of Glassy Topopah Spring Tuff Under Hydrothermal Conditions," Mater. Res. Soc. Symp. Proc. 84, 737-745 (1986); Lawrence Livermore National Laboratory repcrt UCRL-94664 (1986).

94. K. Knauss, W. Beiriger, and D. Peifer, "Hydrothermal Interaction of Solid Wafers of Topopah Spring Tuff with J-13 Water at $90^{\circ} \mathrm{C}$, and $150^{\circ} \mathrm{C}$ Using Dickson-Type, Gold-Bag Rocking Autoclaves: Long-Term Experiments," Lawrence Livermore iNational Laboratory report UCRL-53722 (1987).

95. K. D. McKeegan et al., "Uranium Transport in Topopah Spring Tuff: An Ion-Microscope Investigation," Materials Research Society Fall 1988 Meeting, W. Lutze anci R. C. Ewing, eds., p. 813 (1989).

96. D. E. Moore, C. A. Marrow, and J. D. Byerlee, "Permeability and Fluid Chemistry Studies of the Topopah Spring Member of the Paintbrush Tuff, Nevada Test Site: Part II," Lawrence Livermore National Laboratory report UCRL-15667 (1985).

97. V. M. Oversby and K. G. Knauss, "Reaction of Bullfrog Tuff with J-13 Well Water at $90^{\circ} \mathrm{C}$ and $150^{\circ} \mathrm{C}$," Lawrence Livermore National Laboratory report UCRL-53442 (1983).

98. V. Oversby, "The Reaction of Topopah Spring Tuff with J-13 Water at $150^{\circ} \mathrm{C}$ - Samples from Drill Cores USWG-1, USWGU-3, USW G-4, and UE-25h\#1," Lawrence Livermore National Laboratory report UCRL-53629 (1985).

99. D. Reed and R. Van Konynenburg, "Effect of Ionizing Radiation on Moist Air Systems," Mater. Res. Soc. Symp. Proc. 112, 393-404 (1987); Lawrence Livermore National Laboratory report UCRL-97936 (1987).

100. R. Van Konynenburg, "Radiation Chemical Eifects in Experiments to Study the Reaction of Glass in a Garnma-Irraciiated Air Groundwater and Tuff Environment," Lawrence Livermore National Laboratory report UCRL-53719 (1986). 
101. T. J. Wolery, D. J. Isherwood, K. J. Jackson, J. M. Delany,

I. Puigdomenech, "EQ3/6: Status and Applications," Proc. of Conf. on the Application of Geochemical Models to High-Level Nuclear Waste Repository Assessment, Oak Ridge, TN, October 2-5, 1984, G. K. Jacobs and S. K. Whatley, eds., NUREG/CP-0062, ORNL/TM-9285, 54-65 (1985); Lawrence Livermore National Laboratory report UCRL-91884 (1984).

102. D. T. Reed," "4. Waste Form Considerations," submitted to the Repository Technology Program (1988).

103. T. Abrajano, J. Bates, T. Gerding, and W. Ebert, "The Reaction of Glass in a Gamma-Irradiated Saturated Tuff Environment, Part III: Long-Term Experiments at $1 \times 10^{4}$ Rad/Hour," Argonne National Laboratory report ANL-88-14 (1988).

104. R. D. Aines, H. C. Weed, and J. K. Bates, "Hydrogen Speciation in Hydrated Layers on Nuclear Waste Glass," Mater. Res. Soc. Symp. Proc. 84, 547-558 (1986); Lawrence Livermore National Laboratory report UCRL-95962 (1987).

105. R. D. Aines, "Plan for Glass Waste Form Testing for NNWSI," Lawrence Livermore National Laboratory report UCRL-21190 (1987).

106. R. D. Aines, "Estimates of Radionuclide Release from Glass Waste Forms in a Tuff Repository and the Effects on Regulatory Compliance," Adv. in Ceram. 20, 91-98 (1986; Lawrence Livermore National Laboratory report UCRL-93735 (1986).

107. R. Aines, "Application of EQ3/6 to Modeling of Nuclear Waste Glass Behavior in a Tuff Repository," Lawrence Livermore National Laboratory report UCRL-20895 (1986).

108. A. Barkatt, W. Sousanpour, A. Barkatt, and M. A. Boromand, "Effects of Metals and Metal Oxides on the Leaching of Nuclear Waste Glasses," Mater. Res. Soc. Symp. Proc. 26, 689-696 (1984).

109. G. Bart, E. T. Aerne, R. Grauer, H. Linder, D. Z'Berg, and

H. U. Zwicky, "Surface Film Characterization of Corroded HLW Glass Specimens," Mater. Res. Soc. Symp. Proc. 44, 213-220 (1985).

i10. F. Bazan and J. Rego, "Parametric Testing of a DWPF Borosilicate Glass," Mater. Res. Soc. Symp. Proc. 44, 303-310 (1985); Lawrence Livermore National Laboratory report UCRL-90857 (1985).

111. F. Bazan and J. Rego, "Parametric Testing of a DWPF Glass," Lawrence Livermore National Laboratory report UCRI-53606 (1985).

112. F. Bazan and J. H. Rego, "The Tuff Reaction Vessel Experiment," Lawrence Livermore National Laboratory report UCRL-53735 (1986).

113. F. Bazan, J. Rego, and R. Aines, "Leaching of Actinide-Doped Nuclear Waste Glass in a Tuff-Dominated System," Mater. Res. Soc. Symp. Proc. 84, 447-458 (1986); Lawrence Livermore National Laboratory report UCRL-94721 (1987). 
114. N. E. Bibler, "Leaching Fully Radicactive SRP Nuclear Waste Glass in Tuff Groundwater in Stainless Steel Vessels," Savannah River Laboratory report DP-MS-85-141 (1985).

115. N. E. Bibler and A. R. Jurgensen, "Learhing Tc-99 from DWPF Giass in Simulated Geologic Repository Groundwaters," Savannah River Laboratory internal memo DPST-85-692 (1986).

116. N. E. Bibler and A. R. Jurgensen, "Leaching Tc-99 from SRP Glass in Simulated Tuff and Salt Groundwaters," Mat. Res. Soc. Symp. Proc. Vol. 112, 585-593 (1988).

117. W. L. Bourcier, K. G. Knauss, and C. I. Merzbacher, "A Kinetic Model for the Dissolution cf Borosilicate Glasses:" Lawrence Livermore National Laboratory report UCRL-101285 (1989).

118. W. L. Bourcier, "Geochernical Modeling of Radioactive Waste Glass Dissolutior Using EQ3/6: Preliminary Results and Data Needs," Lawrence Livermore National Laboratory report UCID-21869 (1990).

119. C. Bruton, "Geochemical Simulation of Dissolution of West Valley and DWPF Glasses in J-13 Water at $90^{\circ} \mathrm{C}$," Mater. Res. Soc. Symp.

Proc. 112, 607-619 (1987); Lawrence Livermore National Laboratory report UCRL-96703 (1987).

120. C. Q. Buckwalter and L. R. Pederson, "Inhibition of Nuclear Waste Glass Leaching by Chemisorption," J. Am. Ceram. Soc. 65(9), 431-436 (1982).

121. D. G. Coles and M. J. Apted, "The Behavior of ${ }^{99} \mathrm{Tc}$ in Doped-Glass/ Basalt Hydrothermal Interactions Tests," Mater. Res. Soc. Symp. Proc. 26, 129-136 (1984).

122. W. Ebert, J. Bates, T. Gerding, and R. Van Konynenburg, "The Effects of Gamma Radiation on Groundwater Chemistry and Glass Reacrion in a Saturated Tuff Environment," Mater. Res. Soc. Symp. Proc. 84, 613-622 (1986); Lawrence Livermore National Laboratory report UCRL-95884 $(1986)$.

123. W. Ebert, J. Bates, and T. Gerding, "The Reaction of Glass During Gamma Irradiation in a Saturated Tuff Environment, Part 4: SRL 165, ATM-1c, and ATM-8 Glasses at $1 \mathrm{E3} \mathrm{R} / \mathrm{h}$ and $0 \mathrm{R} / \mathrm{h},{ }^{,}$Argonne National Laboratory report ANL-90/13 (1990).

124. F. T. Ewart, J. B. Morris, J. Severn, B. M. Sharpe, and H. P. Thomason, "The Source Term for the Release of Nuclides from a Radioactive Waste Repository: I. Vitrified Waste in Granite," Mater. Res. Soc. Symp. Proc. 26, 171-178 (1984).

125. H. P. Hermansson, H. Christensen, D. E. Clark, I. K. Bjorner, H. Yokoyama, and L. "Werme, "Static Leaching of Radioactive Glass Under Conditions Simulating a Granitic Repository for High-Level Waste: Phase I," Mater. Res. Soc. Symp. Proc. 26, 671-679 (1984). 
126. K. Ishiguro, N. Sasaki, H. Kashihara, ard M. Yamamoto, "Effects of Rocks and Backfill Materials on Waste Glass Leaching," Mater. Res. Soc. Symp. Proc. 50, 247-254 (1986).

127. C. M. Jantzen, "Effects of Eh (Oxidation Potential) on Borosilicate Waste Glass Durability," Adv. in Ceram. 8, 385-392 (1984).

128. C. M. Jantzen and N. E. Bibler, "The Role of Groundwater Oxidation Potential and Radiolysis on Waste Glass Performance in Crystalline Repository Environments," Mater. Res, Soc. Symp. Proc. 50, 219-230 (1986).

129. C. M. Jantzen and G. G. Wicks, "Control of Oxidation Potential for Basalt Repository Simulation Tests," Mater. Res. Soc. Symp. Proc. 44, 29-35 (1985).

130. H-P. Hermansson, I-K. Bjorner, H. Christensen, and H. Yokoyama, "JSS-Project Phase I: Static Leaching in Distilled Water, Silicate Water, and Simulated Groundwater at $90^{\circ} \mathrm{C}$ with and without Granite. Studsvik's Final Report," JSS Technical Report 84-01, SKB (1984).

131. G. Bart, E. T. Aerne, W. Gorlich, R. Grauer, H. Linder, M. Mokos, D. Z'Berg, and H. U. Zwicky, "EIR Final Report of JSS Glass Corrosion Programme Phase I," JSS Technical Peport 84-02, SKB (1984).

132. "JSS-Project Phase II: Final Report of Work Performed at Studsvik Energiteknik $A B$ and at Swiss Federal Institute for Reactor Research," JSS Technical Report 85-01, SKB (1985).

133. "JSS-Project Phase III. Final Report of Work Performed at Studsvik Energiteknik AB and at Swiss Federal Institute for Reactor Research," JSS Technical Report 86-01, SKE (1985).

134. "JSS-Project Phase IV: Final Report: Experimental and Modeling Studies of HLW Glass Dissolution in Repository Environments," JSS Technical Report 87-01, SKB (1987).

135. B. Grambow, "Nuclear Waste Glass Dissolution: Mechanism, Model and Application," JSS Technical Report 87-02, SKB (1987).

136. D. L. Lane, T. E. Jones, and M. H. West, "Preliminary Assessment of Oxygen Consumption and Redox Conditions in a Nuclear Waste Repository in Basalt," Geochemical Behavior of Disposed Radioactive Waste, ACS Symp. Ser. 246, 181-195 (1984).

137. G. L. McVay and C. Q. Buckwalter, "Effect of Iron on Waste-Glass Leaching," J. Am. Ceram. Soc. 66(3), 170-174 (1983).

138. G. L. McVay and G. R. Robinson, "Effects of Tuff Waste Package Components on Release From 76-68 Simulated Waste Glass," Pacific Northwest Laboratury report PNL-4897. 
139. V. M. Oversby and R. D. McCright, "Laboratory Experiments Designed to Provide Limits on the Radionuclide Source Term for the NNWSI Project," Proc. of Workshop on the Source Term for Radionuclide Migration from HLW or Spent Nuclear Fuel, Albuquerque, NM, SAND85-0380, 175-186, November 13-15, 1984; Lawrence Livermore National Laboratory report UCRL-91257 (1984).

140. R. D. Peters and H. Diamond, "Actinide Leaching from Waste Glass: Air Equilibrated Versus Deaerated Conditions," Pacific Northwest Laboratory report PNL-3971 (1981).

141. D. Phinney, R. Ryerson, V. Oversby, R. Lanford, R. Aines, and J. Bates, "Integrated Testing of SRL-165 Glass Waste Form," Mater. Res. Soc. Symp. Proc. 84, 433-446 (1986); Lawrence Livermore National Laboratory report UCRL-94658 (1986).

142. G. L. Pine and C. M. Jantzen, "Implications of One-Year Basalt Weathering/Reactivity Study for a Basalt Repository Environment," Savannah River Laboratory report DP-1742 (1987).

143. D. Savage, "The Geochemical Interactions of Simulated Borosilicate Waste Glass, Granite and Water at $100-350^{\circ} \mathrm{C}$ and $50 \mathrm{MPa}, "$ Nucl. Chem. Waste Manage. 6, 15-39 (1986).

144. B. E. Scheetz, S. Komarneni, D. K. Smith, C. A. F. Anderson, S. D. Atkinson, and G. J. McCarthy, "Hydrothermal Interaction of Simulated Nuclear Waste Glass in the Presence of Basalt," Scientific Basis for Nuclear Waste Management II, C. J. M. Northrup, ed., Plenum Press, New York, 207-.214 (1980).

145. J. A. Schramke, S. A. Simonson, and D. G. Coles, “ ${ }^{237} \mathrm{~Np}$ and ${ }^{239} \mathrm{Pu}$ Solution Behavior During Hydrothermal Testing of Simulated Nuclear Waste Glass with Basalt and Steel," Mater. Res. Soc. Symp. Proc. 44, 343-350 (1985).

146. H. Yokoyama, H. P. Hermansson, H. Christensen, I. K. Bjorner, and L. O. Werme, "Corrosion of Simulated Nuclear Waste Glass in a Gamma Radiation Field," Mater. Res. Soc. Symp. Proc. 44, 601-608 (1985).

147. C. Bruton and H. Shaw, "Geochemical Simulation of Reaction between Spent Fuel Waste Form and J-13 Water at 25 and $90^{\circ} \mathrm{C}$," Mater. Res. Soc. Symp. Proc. 112, 485-494 (1987); Lawrence Livermore National Laboratory report UCRL-96702 (1987).

148. V. Oversby and C. Wilson, "Radionuclide Release from PWR Fuels in a Reference Tuff Repository Groundwater," Proc. of the Waste Management '85, Tucson, AZ, Vol. 1, pp. 497-503, March 25-29, 1985; Lawrence Livermore National Laboratory report UCRL-91464 (1985).

149. V. M. Oversby and C. N. Wilson, "Derivation of a Waste Package Source Term for NNWSI from the Results of Laboratory Experiments," Mater.

Res. Soc. Symp. Proc. 50, 337-346 (1985); Lawrence Livermore National Laboratory report UCRL-92096 (1985). 
150. V. M. Oversby, "Spent Fuel as a Waste Form - Data Needs to Allow Long Term Performance Assessment Under Repository Disposal Conditions," Mater. Res. Soc. Symp. Proc. 84, 87-10i (1986); Lawrence Livermore National Laboratory report UCRL-94659 (1986).

151. V. Oversby and H. Shaw, "Spent Fuel Performance Data: An Analysis of Data Relevant to the NNWSI Project," Lawrence Livermore National Laboratory report UCRL-20926 (1987).

152. P. F. Salter, J. R. Burnell, and D. L. Lane, "Overview of the Waste/Barrier/Rock Interactions Testing Program of the Basalt Waste Isolation Project," Adv. in Ceram. 20, 79-90 (1986).

153. H. Shaw, "Plan for Spent Fuel Waste Form Testing for NNWSI," Lawrence Livermore National Laboratory report UCRL-21272 (1987).

154. R. Van Konynenburg, C. Smith, C. Culham, and H. D. Smith, "Carbon-14 in Waste Packages for Spent Fuel in a Tuff Repository," Mater. Res. Soc. Symp. Proc. 84, 185-196 (1986); Lawrence Livermore National Laboratory report UCRL-94708 (1986).

155. C. N. Wilson and V. M. Oversby, "Spent Fuel Cladding Containment Credit Tests," Proc. of the ANS/ASME Waste Management '84, Tucson, AZ, Vol. 1, pp. 569-572, March 11-15, 1984; Lawrence Livermore National Laboratory report UCRL-89869 (1984).

156. C. N. Wilson, "Results from NNWSI Series 1 Spent Fuel Leach Tests," Hanford Engineering Development Laboratory report HEDL-TME-84-30 (1985).

157. C. N. Wilson, "Results from NNWSI Series 3 Spent Fuel Leach Tests," Hanford Engineering Development Laboratory report HEDL-7577 (1986).

158. C. N. Wilson, "Recent Results from NNWSI Spent Fuel Leaching/ Dissolution Tests," Westinghouse Hanford Company report HEDL-SA-3700FP (1987); Lawrence Livermore National Laboratory report UCRL-21019 (1987).

159. C. N. Wilson, "Results from Cycles 1 and 2 of NNWSI Series 2 Spent Fuel Dissolution Tests," Westinghouse Hanford Company report HEDL-TME-85-22 (1987).

160. C. N. Wilson, "Summary of Results from the Series 2 and 3 NNWSI Bare Fuel Dissolution Tests," Mater. Res. Soc. Symp. Proc. 112 (1987).

161. C. N. Wilson and C. Bruton, "Studies on Spent Fuel Dissolution Behavior under Yucca Mountain Repository Conditions," submitted to Amer. Nucl. Soc. Mtg, Indianapolis, IN, April 23-27, 1989; Lawrence Livermore National Laboratory report UCRL-100223 (1989).

162. R. G. Baca, R. C. Arnett, and D. W. Langford, "Modelling Fluid Flow in Fractured-Porous Rock Masses by Finite-Element Techniques," Int. Jour. Numerical Methods in Fluids, 4, 337-348 (1984). 
163. J. Bear and A. Verruijt, "Modeling Groundwater Flow and Pollution," Elsevier Pub., 408 p. (1987).

164. R. Beckman, K. Thomas, and B. Crowe, "Preliminary Report on the Statistical Evaluation of Sorption Data: Sorption as a Function of Mineralogy, Time and Particle Size," Los Alamos National Laboratory report LA-11246-MS (1988).

165. S. R. Brown, "Transport of Fiuid and Electric Current Through a Single Fracture," J. Geophys. Res., 94, 9429-9438 (1989).

166. T. A. Buscheck and J. J. Nitao, "Preliminary Scoping Calculations of Hydrothermal Flow in Variably Saturated, Fractured, Welded Tuff During Engineered Barrier Design Test at the Yucca Mountain Exploratory Shaft Test Site," Lawrence Livermore National Laboratory report UCID-21571 (1988).

167. G. A. Cedenberg and L. E. Greenwade, "Preliminary Geochemical/Geophysical Model of Yucca Mountain," Mater. Res. Soc. Symp. Proc. 112, 331-341 (1988).

168. C. W. Fetter, "Applied Hydrogeology," Merrill Publishing Company, 592 p. (1988).

169. R. A. Freeze and J. A. Cherry, "Groundwater," Prentice-Hall, 604 p. (1979).

170. G. E. Grisak and J. F. Pickens, "Solute Transport Through Fractured Media. 1. The Effect of Matrix Diffusion," Water Res. Res. 16, 719-730 (1980).

171. S. K. Gupta, C. R. Cole, C. T. Kincaid, and A. M. Monti, "Coupled Fluid, Energy, and Solute Transport (CFEST) Model: Formulation and User's Manual," Battelle Mem. Inst. report BMI/ONWI-660 (1987).

172. J. F. Kerrisk, "Solubility Limits on Radionuclide Dissolution at a Yucca Mountain Repository," Los Alamos National Laboratory report LA-9995-MS (1984).

173. W. Lin and W. Daily, "Hydrological Properties of Topopah Spring Tuff Under a Thermal Gradient Laboratory Results," Lawrence Livermore National Laboratory report UCRL-96926 (1988).

174. C. McCombie, "Research Priorities: Are We Tackling the Most Important Problems in Waste Management?" Mat. Res. Soc. Symp. Proc. 127, i-9 (1988).

175. K. D. McKeegan, D. Phinney, V. M. Oversby, M Buchholtz-ten Brink, and D. K. Smith, "Uranium Transport in Topopah Spring Tuff: An Ion Microprobe Investigation," Mat. Res. Soc. Symp. Proc. 127, 813-821 (1989). 
176. R. E. Meyer, W. D. Arnold, J. G. Blencoe, G. D. O'Kelley, F. I. Case, J. F. Land, and G. K. Jacobs, "Progress in Evaluation of Radionuclide Geochemical Information Developed by DOE High-Level Nuclear Waste Repository Site Projects," Oak Ridge National Laboratory report NUREG/CR-4708, ORNL/TM-10147 (1987).

177. H. J. Morel-Seytoux, Ed., "Unsaturated Flow in Hydrologic Modeling," NATO Advanced Study Inst Series, C 275, 552 p. (1989).

178. I. Neretnieks, "Diffusion in the Rock Matrix: An Important Factor in Radionuclide Retardation?" J. Geophys. Res. 85, 4379-4397 (1980).

179. J. J. Nitao, "Simulations of the Near-Field Transport of Radionuclides by Liquid Diffusion at Yucca Mountain -- Comparisons with and without Emplacement Backfill," Lawrence Livermore National Laboratory report UCID-21466 (1988).

180. J. R. Philip, "Theory of Infiltration," In Adv. in Hydroscience 5 , V. T. Chow, ed., Academic Press, New York, 215-296 (1969).

181. R. S. Rundberg, J. L. Thompson, and S. Maestas, "Radionuclide Migration: Laboratory Experiments with Isolated Fractures," Mater. Res. Soc. Symp. Proc. 6, 239-248 (1982).

182. R. S. Rundberg, "Kinetics of the Adsorption of Radionuclides on Tuff from Yucca Mountain," Mat. Res. Soc. Symp. Proc. 26, 827-834 (1984).

183. K. W. Thomas, "Summary of Sorption Measurements Performed with Yucca Mountain, Nevada, Tuff Samples and Water from Well J-13," Los Alamos National Laboratory report LA-10@30-MS (1987).

184. T. C. Yeh, T. C. Rasmussen, and D. D. Evans, "Simulation of Liquid and Vapor Movement in Unsaturated Fractured Rock at the Apache Leap Tuff Site," NUREG/CR-5097 (1988).

185. "Site Characterization Plan," U.S. Department of Energy, Office of Civilian Radioactive Waste Management, DOE report DOE/RW-0199 (1988). 